Foundations and Trends ${ }^{\circledR}$ in

Human-Computer Interaction

Vol. 1, No. 3 (2007) 203-275

(C) 2007 M. A. Goodrich and A. C. Schultz

DOI: $10.1561 / 1100000005$

\title{
Human-Robot Interaction: A Survey
}

\author{
Michael A. Goodrich ${ }^{1}$ and Alan C. Schultz ${ }^{2}$ \\ 1 Brigham Young University, Provo,UT 84602, USA, mike@cs.byu.edu \\ 2 US Naval Research Laboratory, Washington, DC 20375, USA, \\ schultz@aic.nrl.navy.mil
}

\begin{abstract}
Human-Robot Interaction (HRI) has recently received considerable attention in the academic community, in labs, in technology companies, and through the media. Because of this attention, it is desirable to present a survey of HRI to serve as a tutorial to people outside the field and to promote discussion of a unified vision of HRI within the field. The goal of this review is to present a unified treatment of HRI-related problems, to identify key themes, and discuss challenge problems that are likely to shape the field in the near future. Although the review follows a survey structure, the goal of presenting a coherent "story" of HRI means that there are necessarily some well-written, intriguing, and influential papers that are not referenced. Instead of trying to survey every paper, we describe the HRI story from multiple perspectives with an eye toward identifying themes that cross applications. The survey attempts to include papers that represent a fair cross section of the universities, government efforts, industry labs, and countries that contribute to HRI, and a cross section of the disciplines that contribute to the field, such as human, factors, robotics, cognitive psychology, and design.
\end{abstract}




\section{Report Documentation Page}

Public reporting burden for the collection of information is estimated to average 1 hour per response, including the time for reviewing instructions, searching existing data sources, gathering and maintaining the data needed, and completing and reviewing the collection of information. Send comments regarding this burden estimate or any other aspect of this collection of information, including suggestions for reducing this burden, to Washington Headquarters Services, Directorate for Information Operations and Reports, 1215 Jefferson Davis Highway, Suite 1204, Arlington VA 22202-4302. Respondents should be aware that notwithstanding any other provision of law, no person shall be subject to a penalty for failing to comply with a collection of information if it does not display a currently valid OMB control number.

\begin{tabular}{|c|c|c|}
\hline $\begin{array}{l}\text { 1. REPORT DATE } \\
\mathbf{2 0 0 7}\end{array}$ & 2. REPORT TYPE & $\begin{array}{l}\text { 3. DATES COVERED } \\
\mathbf{0 0 - 0 0 - 2 0 0 7} \text { to 00-00-2007 }\end{array}$ \\
\hline \multirow{3}{*}{\multicolumn{2}{|c|}{$\begin{array}{l}\text { 4. TITLE AND SUBTITLE } \\
\text { Human-Robot Interaction: A Survey }\end{array}$}} & 5a. CONTRACT NUMBER \\
\hline & & 5b. GRANT NUMBER \\
\hline & & 5c. PROGRAM ELEMENT NUMBER \\
\hline \multirow{3}{*}{\multicolumn{2}{|c|}{ 6. AUTHOR(S) }} & 5d. PROJECT NUMBER \\
\hline & & 5e. TASK NUMBER \\
\hline & & 5f. WORK UNIT NUMBER \\
\hline \multicolumn{2}{|c|}{$\begin{array}{l}\text { 7. PERFORMING ORGANIZATION NAME(S) AND ADDRESS(ES) } \\
\text { US Naval Research Laboratory, Washington,DC,20375 }\end{array}$} & $\begin{array}{l}\text { 8. PERFORMING ORGANIZATION } \\
\text { REPORT NUMBER }\end{array}$ \\
\hline \multirow{2}{*}{\multicolumn{2}{|c|}{ 9. SPONSORING/MONITORING AGENCY NAME(S) AND ADDRESS(ES) }} & 10. SPONSOR/MONITOR'S ACRONYM(S) \\
\hline & & $\begin{array}{l}\text { 11. SPONSOR/MONITOR'S REPORT } \\
\text { NUMBER(S) }\end{array}$ \\
\hline
\end{tabular}

12. DISTRIBUTION/AVAILABILITY STATEMENT

Approved for public release; distribution unlimited

13. SUPPLEMENTARY NOTES

14. ABSTRACT

Human-Robot Interaction (HRI) has recently received considerable attention in the academic community, in labs, in technology companies, and through the media. Because of this attention, it is desirable to present a survey of HRI to serve as a tutorial to people outside the field and to promote discussion of a unified vision of HRI within the field. The goal of this review is to present a unified treatment of HRI-related problems, to identify key themes, and discuss challenge problems that are likely to shape the field in the near future. Although the review follows a survey structure, the goal of presenting a coherent "story" of HRI means that there are necessarily some well-written, intriguing, and influential papers that are not referenced. Instead of trying to survey every paper, we describe the HRI story from multiple perspectives with an eye toward identifying themes that cross applications. The survey attempts to include papers that represent a fair cross section of the universities, government efforts, industry labs, and countries that contribute to HRI, and a cross section of the disciplines that contribute to the field, such as human, factors, robotics, cognitive psychology, and design.

15. SUBJECT TERMS

16. SECURITY CLASSIFICATION OF:

a. REPORT

unclassified b. ABSTRACT

unclassified c. THIS PAGE unclassified
17. LIMITATION OF ABSTRACT

Same as Report (SAR)
18. NUMBER OF PAGES

73 19a. NAME OF RESPONSIBLE PERSON 


\section{1}

\section{Introduction}

Human-Robot Interaction (HRI) is a field of study dedicated to understanding, designing, and evaluating robotic systems for use by or with humans. Interaction, by definition, requires communication between robots and humans. Communication between a human and a robot may take several forms, but these forms are largely influenced by whether the human and the robot are in close proximity to each other or not. Thus, communication and, therefore, interaction can be separated into two general categories:

- Remote interaction - The human and the robot are not colocated and are separated spatially or even temporally (for example, the Mars Rovers are separated from earth both in space and time).

- Proximate interaction - The humans and the robots are colocated (for example, service robots may be in the same room as humans).

Within these general categories, it is useful to distinguish between applications that require mobility, physical manipulation, or social interaction. Remote interaction with mobile robots is often referred 
to as teleoperation or supervisory control, and remote interaction with a physical manipulator is often referred to as telemanipulation. Proximate interaction with mobile robots may take the form of a robot assistant, and proximate interaction may include a physical interaction. Social interaction includes social, emotive, and cognitive aspects of interaction. In social interaction, the humans and robots interact as peers or companions. Importantly, social interactions with robots appear to be proximate rather than remote. Because the volume of work in social interactions is vast, we present only a brief survey; a more complete survey of this important area is left to future work.

In this review, we present a survey of modern HRI. We begin by presenting key developments in HRI-related fields with the goal of identifying critical technological and scientific developments that have made it possible for HRI to develop as a field of its own. We argue that HRI is not simply a reframing and reformulation of previous work, but rather a new field of scientific study. To support this argument, we identify seminal events that signal the emergence of HRI as a field. Although we adopt a designer-centered framing of the review, work in the field requires strong interdisciplinary blends from various scientific and engineering fields.

After surveying key aspects in the emergence of HRI as a field, we define the HRI problem with an emphasis on those factors of interaction that a designer can shape. We then proceed to describe the application areas that drive much of modern HRI. Many of these problems are extremely challenging and have strong societal implications. We group application areas into the previously mentioned two general categories, remote and proximate interactions, and identify important, influential, or thought-provoking work within these two categories. We follow this by describing common solution concepts and barrier problems that cross application domains and interaction types. We then briefly identify related work from other fields involving humans and machines interacting, and summarize the review. 


\section{Early History of Robotics and Human-Machine-Interaction}

In this section, we briefly survey events and work that have made modern HRI possible. Clearly, the development of robots was the essential first step. Although robot technology was primarily developed in the mid and late 20th century, it is important to note that the notion of robot-like behavior and its implications for humans have been around for centuries in religion, mythology, philosophy, and fiction. The word "robot" originates from the Czechoslovakian word robota which means work [309]. "Robot" appears to have first been used in Karel Chapek's 1920's play Rossum's Universal Robots, though this was by no means the earliest example of a human-like machine. Indeed, Leonardo da Vinci sketched a mechanical man around 1495, which has been evaluated for feasibility in modern times [250]. Pre-dating da Vinci's humanoid robot are automata and mechanical creatures from ancient Egypt, Greece, and China. The Iliad refers to golden maids that behave like real people [125]. The idea of golem, an "artificial being of Hebrew folklore endowed with life" has been around for centuries [309] and was discussed by Wiener in one of his books [315]. Ancient Chinese legends and compilations mention robot-like creations, such as the story from the West Zhou Dynasty (1066BC-771BC) that 
describes how the craftsman Yanshi presented a humanoid. The creation looked and moved so much like a human that, when it winked at the concubines, it was necessary to dismantle it to prove that it was an artificial creation [328]. Similar robotic devices, such as a wooden ox and floating horse, were believed to have been invented by the Chinese strategist Zhuge Liang [316], and a famous Chinese carpenter was reported to have created a wooden/bamboo magpie that could stay aloft for up to three days [297]. More recently, robotic-like automata, including Vaucanson's duck, have been created [243]. Mechanical-like birds were present in the 1933 poem Byzantium by W. B. Yeats [326], and robots have had a large presence in science fiction literature, most notably Azimov's works [12]. Indeed, Asimov's Laws of Robotics appear to be the first designer guidelines for HRI.

Early robot implementations were remotely operated devices with no or minimal autonomy (Figure 2.1). In 1898, Nicola Tesla demonstrated a radio-controlled boat, which he described as incorporating "a borrowed mind." In fact, Tesla controlled the boat remotely. His invention, which he generalized to many different types of vehicles, was described in patent 613,809, "Method and Apparatus for Controlling Mechanism of Moving Vessels." Tesla hypothesized, “... you see there

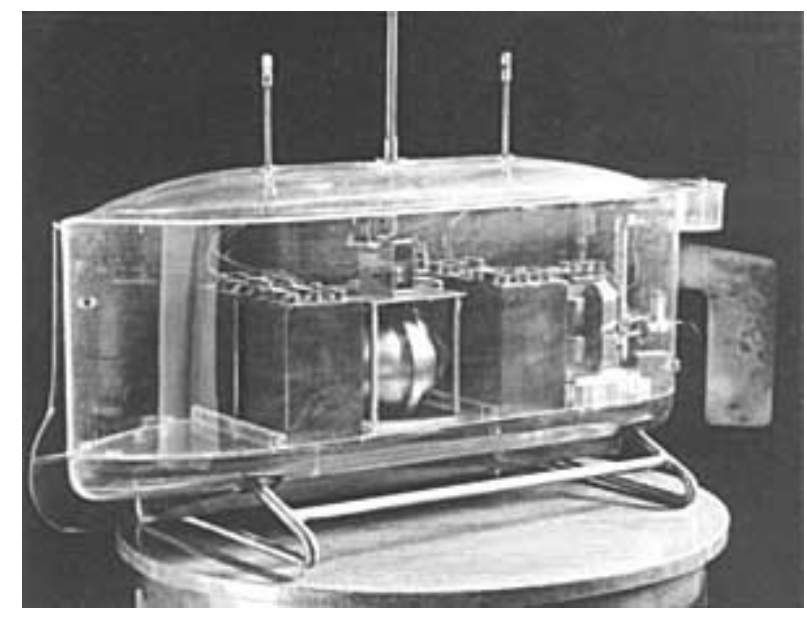

Fig. 2.1 Tesla's boat [287]. 
the first of a race of robots, mechanical men which will do the laborious work of the human race." He even envisioned one or more operators simultaneously directing 50 or 100 vehicles.

Other examples include: The Naval Research Laboratory's "Electric Dog" robot from 1923, attempts to remotely pilot bombers during World War II, the creation of remotely piloted vehicles, and mechanical creatures designed to give the appearance of life. As technology evolved, the capabilities of remotely operated robots have grown (see [95] for a brief history). This is perhaps nowhere more evident then in the very successful application of unmanned underwater vehicles that have been used to explore the ocean's surface to find lost ships, explore underwater life, assist in underwater construction, and study geothermal activity [313].

Complementing the advances in robot mechanics, research in artificial intelligence has attempted to develop fully autonomous robots. The most commonly cited example of an early autonomous robot was Shakey, which was capable of navigating through a block world under carefully controlled lighting conditions at the glacially slow speed of approximately 2 meters per hour [209]. Many agree that these early works laid a foundation for much that goes on in hybrid control architectures today [196, 223].

A breakthrough in autonomous robot technology occurred in the mid 1980s with work in behavior-based robotics [10, 38]. Indeed, it could be argued that this work is a foundation for many current robotic applications. Behavior-based robotics breaks with the monolithic senseplan-act loop of a centralized system, and instead uses distributed sense-response loops to generate appropriate responses to external stimuli. The combination of these distributed responses produces "emergent" behavior that can produce very sophisticated responses that are robust to changes in the environment. A second important breakthrough for autonomy as it applies to HRI is the emergence of hybrid architectures; these architectures simultaneously allow sophisticated reactive behaviors that provide fundamental robot capabilities along with the high-level cognitive reasoning required for complex and enduring interactions with humans. Robot behaviors initially focused on mobility, but more recent contributions seek to develop lifelike anthro- 
pomorphic behaviors [323], acceptable behaviors of household robots [158], and desirable behaviors for robots that follow, pass, or approach humans [105, 220, 307].

The development of robust robot platforms and communications technologies for extreme environments has been accomplished by NASA and other international space agencies. Space agencies have had several high profile robotic projects, designed with an eye toward safely exploring remote planets and moons. Examples include early successes of the Soviet Lunokhods [95] and NASA's more recent success of exploring the surface of Mars [174, 317]. Importantly, many of the failures have been the result of software problems rather than mechanical failures. Complementing NASA's fielded robots have been several robots developed and evaluated on earth [17]. Robonaut is a well-known example of successful teleoperation of a humanoid robot [9], and this work is being extended at a rapid pace to include autonomous movement and reasoning. Autonomous robots that have the anthropomorphic dimensions, mimic human-like behaviors, and include human-like reasoning are known as humanoid robots; work in this area has been ongoing for over a decade and is rapidly expanding [9, 23, 31, 37, 153, 273, 285].

Emerging from the early work in robotics, human factors experts have given considerable attention to two paradigms for human-robot interaction: teleoperation and supervisory control. At the teleoperation extreme, a human remotely controls a mobile robot or robotic arm. With supervisory control, a human supervises the behavior of an autonomous system and intervenes as necessary. Early work was usually performed by people who were interested not only in robotics but also factory automation, aviation, and intelligent vehicles. Work in these areas is typified by Sheridan's seminal contributions [267, 268], and other significant contributions from human factors researchers $[193,314]$.

Every robot application appears to have some form of interaction, even those that might be considered "fully autonomous." For a teleoperated robot, the type of interaction is obvious. For a fully autonomous robot, the interaction may consist of high-level supervision and direction of the robot, with the human providing goals and with the robot maintaining knowledge about the world, the task and its constraints. 
In addition, the interactions may be through observation of the environment and implicit communications by, for example, the robot responding to what its human peer is doing. Taking a very broad and general view of HRI, one might consider that it includes developing algorithms, programming, testing, refining, fielding, and maintaining the robots. In this case, interaction consists primarily in discovering and diagnosing problems, solving these problems, and then reprogramming (or rewiring) the robot. The difference between this type of "programmingbased" interaction and modern HRI is that the field currently emphasizes efficient and dynamic interactions rather than just infrequent interactions. However, some researchers are addressing programmingbased of interaction by exploring efficient programming paradigms to support robot development [128, 327]. 


\section{Emergence of $\mathrm{HRI}$ as a Field}

Although there is much work that can be considered HRI, the multidisciplinary field started to emerge in the mid 1990s and early years of 2000. Key numerous events occurred in this time frame, with the main catalyst being a multi-disciplinary approach; researchers from robotics, cognitive science, human factors, natural language, psychology, and human-computer interaction started to come together at these events specifically recognizing the importance of working together.

The earliest scientific meeting, which started in 1992 and continues annually, is the IEEE International Symposium on Robot \& Human Interactive Communication (RoMan). Although recently this conference has attracted a more multi-disciplinary research community, historically it has been heavily dominated by the robotics discipline. In 2000, the IEEE/Robotics Society of Japan created the International Conference on Humanoid Robots which highlights anthropomorphic robots and robotic behaviors.

From the late 1990s until recently, there have been many workshops and conference tracks dedicated to HRI, including ones associated with the Association for the Advancement of Artificial Intelligence's (AAAI) Symposia Series, IEEE International Conference on 
Robotics and Automation (ICRA), Robotics Systems and Sciences, the IEEE/Robotics Society of Japan International Conference on Intelligent Robot and Systems, among others, and the annual meeting of the Human Factors and Ergonomics Society.

In 2001, the US National Science Foundation and Defense Advanced Research Projects Agency sponsored a workshop on human-robot interaction, organized by Dr Robin Murphy and Dr Erica Rogers [46]. The purpose of this workshop was to bring together a highly multidisciplinary group of researchers working in areas close to HRI, and to help identify the issues and challenges in HRI research. Although much research had been done prior to this event, some consider it to be seminal in the emergence of the field as its own discipline. A second NSF workshop was held in 2006 [181].

In July 2004, IEEE-RAS and the International Foundation of Robotics Research (IFRR) sponsored a summer school on "HumanRobot Interaction." This event brought together six experts from the field of HRI and approximately $30 \mathrm{PhD}$ students for a week in Volterra Italy for four intensive days of lectures and events. A similar event that has been held annually since 2004 is the Rescue Robotics Camp (see, for example, [239, 240]). About the same time, a series of special issues dedicated to HRI began to appear in journals $[5,157,171,201,261]$.

In 2005, the US National Research Council sponsored a workshop entitled "Interfaces for Ground and Air Military Robots" [64]. The workshop discussed emerging interface and autonomy themes that could be used across multiple scales to support primarily remote interaction of humans and robots.

The Japan Association for the 2005 World Exposition conducted a Robot Project at EXPO 2005 that featured a wide range of robots [6]. Guide, cleaning, service, and assistive robots were among the many robots that were featured.

Starting in 2006, the ACM International Conference on HumanRobot Interaction was created to specifically address the multidisciplinary aspects of HRI research. Reflecting this multidisciplinary nature, the 2007 conference was co-sponsored by the ACM Special Interest Group on Computer Human Interaction, the ACM Special 
Interest Group on Artificial Intelligence, and the IEEE Robotics and Automation Society (RAS), with co-technical sponsorship from AAAI, the Human Factors and Ergonomics Society, and the IEEE Systems, Man, and Cybernetics Society. Associated with the HRI conference is a NSF-funded student workshop. Other conferences have had a strong interest in HRI including the following: the Humanoid Robotics workshops; the IEEE International Workshop on Safety, Security, and Rescue Robotics; and the Performance Metrics for Intelligent Systems workshop.

In 2006, the European Land-Robot Trial (ELROB) was created to "provide an overview of the European state-of-the-art in the field of [Unmanned Ground Vehicles]" [87]. Such systems frequently included robust user interfaces intended for field conditions in challenging environments, such as those faced in military and first responder domains.

Another big influence in the emergence of HRI has been competitions. The two with the greatest impact have been (a) the AAAI Robotics Competition and Exhibition and (b) the Robocup Search and Rescue competition. The Sixth AAAI Robot Competition in 1997 had the first competition specifically designed for HRI research called "Hors d'Oeuvres Anyone?" The goal of the competition was for a robot to serve snacks to attendees of the conference during the conference reception. This event was repeated in 1998. Starting in 1999, a new grand challenge event was introduced. For this competition, a team's robot had to be dropped off at the front door of the conference venue and, through interaction with people, find its way to the registration desk, register for the conference, and then find its way at the correct time to a place where it was to give a presentation. This task was designed to be hard enough to take many years to accomplish, helping to drive research (see, for example, [276]). In recent years this conference held several general human-interaction events.

In some cases, an application domain has helped to draw the field together. Three very influential areas are robot-assisted search and rescue, assistive robots, and space exploration. Literature from each of these domains is addressed further in a subsequent section. Robot-assisted search and rescue has been a domain in which the 


\section{Emergence of HRI as a Field}

robotics field has worked directly with the end users which, in this case, consists of specially trained rescue personnel. The typical search and rescue situation involves using a small robot to enter into a potentially dangerous rubble pile to search for victims of a building collapse. The robots are typically equipped with a video camera and possibly chemical and temperature sensors, and may sometimes be equipped with a manipulator with which they can alter the environment. The goal is to quickly survey an area that would otherwise be unsafe for a human searcher to enter, and gather information about victim location and structural stability. Because of the inherently unstructured nature of search and rescue domains, the interactions between the human and the robot are very rich. Consequently, many HRI issues are addressed in the problem, and several ongoing competitions are held to encourage robotics researchers to participate $[159,199,325]$.

Assistive robot systems seek to provide physical, mental, or social support to persons who could benefit from it such as the elderly or disabled. Assistive robotics is important to HRI because it emphasizes proximate interaction with potentially disabled persons. HRI challenges from this domain include providing safe physical contact or moving within very close proximity. The challenges also include supporting effective social interactions through cognitive and emotive computing, and through natural interactions such as gesture and speech. Although sometimes referred to by names other than robots, the types of robots/machines used in assistive applications vary widely in their physical appearance, and include wheelchairs, mobile robots with manipulators, animal-like robots, and humanoids [90, 206, 246, 299]. Because of the close proximity and sometimes long-term interactions, appropriate HRI in assistive robotics may be sensitive to cultural influences $[152,270]$.

Space robotics has also been an important domain for HRI because of the challenges that arise under such extreme operating conditions. These challenges include operating a remote robot when the time lag can be a significant factor, or interacting in close proximity such as when a robot assistant helps an astronaut in exploring the surface of a planetary body. A typical anticipated situation is a geological 
study that involves prolonged work on the surface of a planetary body, possibly using specialized sensors such as ground-penetrating radar and specialized manipulators such as a drill and hammer [84]. Information gathered by the robot needs to be returned either (a) to an astronaut who is co-located with the robot or (b) to a ground-bases science team who then form real-time hypotheses that are used to modify the behavior of the robot. 


\section{What Defines an HRI Problem?}

The HRI problem is to understand and shape the interactions between one or more humans and one or more robots. Interactions between humans and robots are inherently present in all of robotics, even for so called autonomous robots - after all, robots are still used by and are doing work for humans. As a result, evaluating the capabilities of humans and robots, and designing the technologies and training that produce desirable interactions are essential components of HRI. Such work is inherently interdisciplinary in nature, requiring contributions from cognitive science, linguistics, and psychology; from engineering, mathematics, and computer science; and from human factors engineering and design.

Although analysis of anticipated and existing interaction patterns is essential, it is helpful to adopt the designer's perspective by breaking the HRI problem into its constituent parts. In essence, a designer can affect five attributes that affect the interactions between humans and robots:

- Level and behavior of autonomy,

- Nature of information exchange,

- Structure of the team, 
- Adaptation, learning, and training of people and the robot, and

- Shape of the task.

Interaction, the process of working together to accomplish a goal, emerges from the confluence of these factors. The designer attempts to understand and shape the interaction itself, with the objective of making the exchange between humans and robots beneficial in some sense. We now discuss each of these attributes in detail, including references from the literature.

\subsection{Autonomy}

Designing autonomy consists of mapping inputs from the environment into actuator movements, representational schemas, or speech acts. There are numerous formal definitions of autonomy and intelligence in the literature $[7,20,119,184,256]$, many of which arise in discussions of adjustable or dynamic autonomy [30]. One operational characterization of autonomy that applies to mobile robots is the amount of time that a robot can be neglected, or the neglect tolerance of the robot [68]. A system with a high level of autonomy is one that can be neglected for a long period of time without interaction. However, this notion of autonomy does not encompass Turing-type notions of intelligence that might be more applicable to representational or speech-act aspects of autonomy.

Autonomy is not an end in itself in the field of HRI, but rather a means to supporting productive interaction. Indeed, autonomy is only useful insofar as it supports beneficial interaction between a human and a robot. Consequently, the physical embodiment and type of autonomy varies dramatically across robot platforms; see Figure 4.1, which shows a cross section of the very many different types of physical robots.

Perhaps the most strongly human-centered application of the concept of autonomy is in the notion of level of autonomy ( $L O A)$. Levels of autonomy describe to what degree the robot can act on its own accord. Although many descriptions of LOA have been seen in the literature, the most widely cited description is by Tom Sheridan [269]. In Sheridan's scale, there is a continuum from the entity being completely con- 


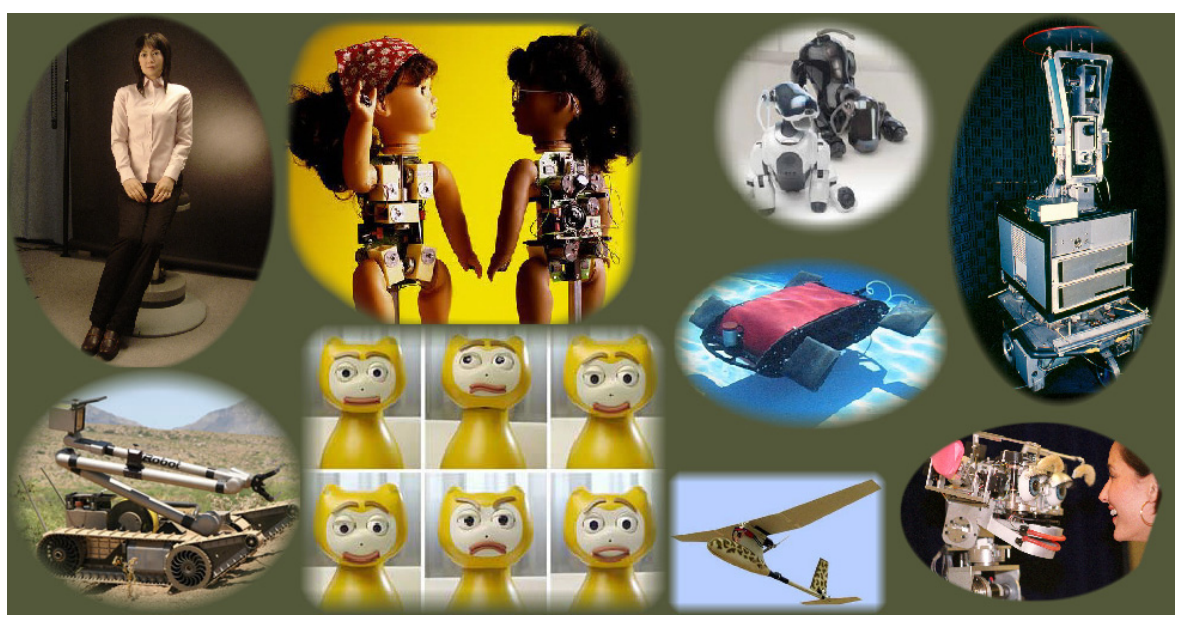

Fig. 4.1 Representative types of robots. In clockwise order beginning in the upper left: RepileeQ2 - an extremely sophisticated humanoid [136]; Robota — humanoid robots as "educational toys" [21]; SonyAIBO — a popular robot dog ; (below the AIBO) A sophisticated unmanned underwater vehicle [176]; Shakey - one of the first modern robots, courtesy of SRI International, Menlo Park, CA [279]; Kismet - an anthropomorphic robot with exaggerated emotion [65]; Raven — a mini-UAV used by the US military [186]; iCAT an emotive robot $[\mathrm{REF}]$; iRobot ${ }^{\circledR}$ PackBot ${ }^{\circledR}$ - a robust ground robot used in military applications [135]. (All images used with permission.)

trolled by a human (i.e., teleoperated), through the entity being completely autonomous and not requiring input or approval of its actions from a human before taking actions:

1. Computer offers no assistance; human does it all.

2. Computer offers a complete set of action alternatives.

3. Computer narrows the selection down to a few choices.

4. Computer suggests a single action.

5. Computer executes that action if human approves.

6. Computer allows the human limited time to veto before automatic execution.

7. Computer executes automatically then necessarily informs the human.

8. Computer informs human after automatic execution only if human asks. 
9. Computer informs human after automatic execution only if it decides too.

10. Computer decides everything and acts autonomously, ignoring the human.

Variations of this scale have been developed and used by various authors [144, 222]. Importantly, Miller and Parasuraman have noted that such scales may not be applicable to an entire problem domain but are rather most useful when applied to each subtask within a problem domain [188]. The authors further suggest that previous scales actually represent an average over all tasks.

While such (average) scales are appropriate to describe how autonomous a robot is, from a human-robot interaction point of view, a complementary way to consider autonomy is by describing to what level the human and robot interact and the degree to which each is capable of autonomy. The scale presented in Figure 4.2 gives an emphasis to mixed-initiative interaction, which has been defined as a "flexible interaction strategy in which each agent (human and [robot]) contributes what it is best suited at the most appropriate time" [122]. Various and different HRI issues arise along this scale. On the direct control side, the issues tend toward making a user interface that reduces the cognitive load of the operator. On the other extreme of peerto-peer collaboration, issues arise in how to create robots with the appropriate cognitive skills to interact naturally or efficiently with a human.

Note that in order for the robot to achieve peer-to-peer collaboration, it must indeed be able to flexibly exhibit "full autonomy" at appropriate times. Moreover, it may need to support social interactions.

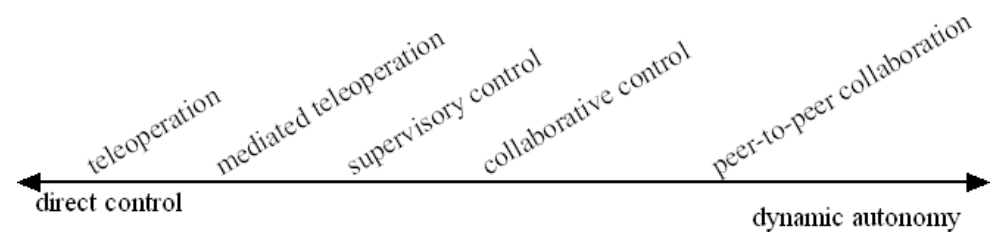

Fig. 4.2 Levels of autonomy with emphasis on human interaction. 
As a result, peer-to-peer collaboration may be considered more difficult to achieve than full autonomy.

Autonomy is implemented using techniques from control theory, artificial intelligence, signal processing, cognitive science, and linguistics. A common autonomy approach is sometimes referred to as the sense-plan-act model of decision-making [196]. This model has been a target of criticism [39] and sometimes rightfully so, but much of the criticism may be a function of the early capacities of robots such as Shakey [209] rather than failings of the model per se. This model is typified by artificial intelligence techniques, such as logics and planning algorithms [253]. The model can also incorporate control theoretic concepts, which have been used very successfully in aviation, aeronautics, missile control, and etc. (see, for example, [175]).

In the mid 1980s, Brooks, Arkin, and others revolutionized the field of robotics by introducing a new autonomy paradigm that came to be known as behavior-based robotics. In this paradigm, behavior is generated from a set of carefully designed autonomy modules that are then integrated to create an emergent system [10, 38, 40]. These modules generate reactive behaviors that map sensors directly to actions, sometimes with no intervening internal representations. This model for behavior generation was accompanied by hardware development that allowed autonomy modules to be implemented in the small form factors required for many robotics applications.

Today, many researchers build sense-think-act models on top of a behavior-based substrate to create hybrid architectures [196]. In these systems, the low-level reactivity is separated from higher level reasoning about plans and goals [28]. Some have developed mathematics and frameworks that can be viewed as formalizations of hybrid architectures and which are referred to as theories of intelligent control [7, 255]. Interestingly, some of the most challenging problems in developing (hybrid) behaviors is in producing natural and robust activity for a humanoid robot $[194,273,323]$.

Complementing the advancement of robotic control algorithms has been the advancement of sensors, sensor-processing, and reasoning algorithms. This is best represented by the success of the field of probabilistic robotics, typified by probabilistic algorithms for localization 
and mapping [161, 289]. It is no overstatement to say that these algorithms, which frequently exploit data from laser and other range finder devices, have allowed autonomy to become truly useful for mobile robots [290], especially those that require remote interaction through periods of autonomous behavior and autonomous path planning [42, 276, 284, 291, 293]. Although probabilistic algorithms can be computationally expensive, the memory capacity, computational speed, and form factor of modern computers have allowed these algorithms to be deployable.

The areas of representing knowledge and performing reasoning, especially in team contexts, have also grown. Example developments include the emergence of belief-desire-intention architectures [321], joint intention theory [60], affect-based computing [31, 223, 229], and temporal logics.

\subsection{Information Exchange}

Autonomy is only one of the components required to make an interaction beneficial. A second component is the manner in which information is exchanged between the human and the robot (Figure 4.3). Measures of the efficiency of an interaction include the interaction time required for intent and/or instructions to be communicated to the robot [68], the cognitive or mental workload of an interaction [268], the amount of situation awareness produced by the interaction [88] (or reduced because of interruptions from the robot), and the amount of shared understanding or common ground between humans and robots $[143,160]$.

There are two primary dimensions that determine the way information is exchanged between a human and a robot: the communications medium and the format of the communications. The primary media are delineated by three of the five senses: seeing, hearing, and touch. These media are manifested in HRI as follows:

- visual displays, typically presented as graphical user interfaces or augmented reality interfaces [15, 145, 154, 208],

- gestures, including hand and facial movements and by movement-based signaling of intent [31, 73, 247, 305], 


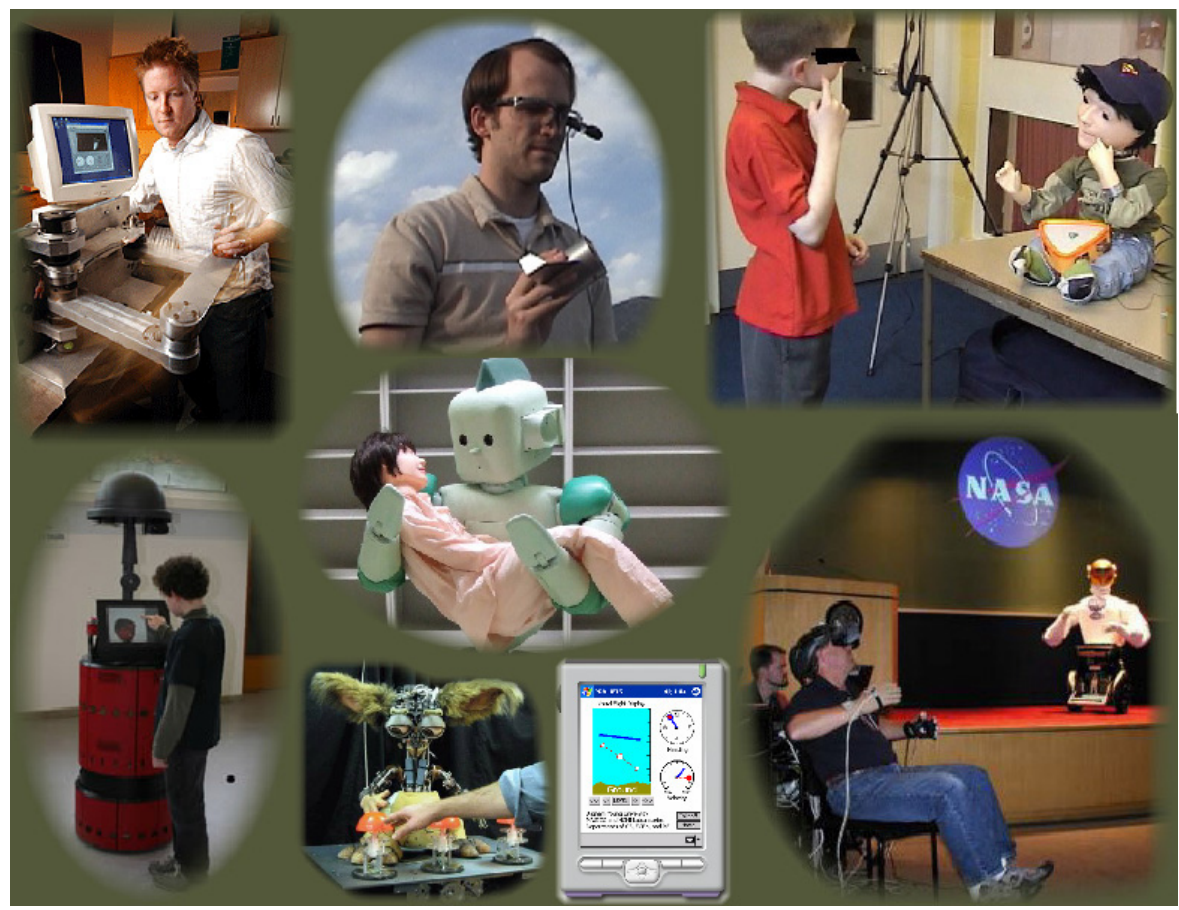

Fig. 4.3 Types of human-robot interaction. Counterclockwise from top left: haptic robot interaction from Georgia Tech [102], a "physical icon" for flying a UAV from Brigham Young University, peer-to-peer interaction with the robot Kaspar from the University of Hertfordshire [298], teleoperation of NASA's Robonaut [205], a PDA-based interface for flying a UAV from Brigham Young University, gesture- and speech-based interaction with MIT's Leonardo [189], a touchscreen interaction with a Cogniron robot [169], and (center) physical interaction with the RI-MAN robot [24]. (All images used with permission.)

- speech and natural language, which include both auditory speech and text-based responses, and which frequently emphasize dialog and mixed-initiative interaction $[126,227]$,

- non-speech audio, frequently used in alerting [78], and

- physical interaction and haptics, frequently used remotely in augmented reality or in teleoperation to invoke a sense of presence especially in telemanipulation tasks [10, 282], and also frequently used proximately to promote emotional, social, and assistive exchanges [56, 124, 172, 272]. 
Recently, attention has focused on building multimodal interfaces [226], partly motivated by a quest to reduce workload in accordance to Wickens' multiple resource theory [314] and partly motivated by a desire to make interactions more natural and easier to learn [248, 254, 281].

The format of the information exchange varies widely across domains. Speech- and natural language-based exchanges can be scripted and based on a formal language, can attempt to support full natural language, or can restrict natural language to a subset of language and a restricted domain (see, for example, [52, 120, 251, 275, 276]). Importantly, speech-based exchanges must not only address the content of information exchanged, but also the rules of such exchange a lá the Gricean maxims [118], which ask to what extent the speech is truthful, relevant, clear, and informative. Haptic information presentation can include giving warnings through vibrations, promoting the feeling of telepresence, supporting spatial awareness through haptic vests, and communicating specific pieces of information through haptic icons (see, for example, [53, 164, 235]). Audio information presentation can include auditory alerts, speech-based information exchange, and 3D awareness (see, for example, [285]). Presenting social information can include attentional cueing, gestures, sharing physical space, imitation, sounds, facial expression, speech and natural language $[22,35,36,83,94,203,149,260]$. Finally, graphical user interfaces present information in ways that include ecological displays, immersive virtual reality, and traditional windows-type interactions (see, for example, $[9,15,185,208])$.

\subsection{Teams}

HRI problems are not restricted to a single human and a single robot, though this is certainly one important type of interaction. Robots used in search and rescue, for example, are typically managed by two or more people, each with special roles in the team [197, 264]. Similarly, managing Unmanned/Uninhabited Air Vehicles (UAVs) is typically performed by at least two people: a "pilot," who is responsible for navigation and control, and a sensor/payload operator, who is responsible for managing cameras, sensors, and other payloads [82, 182]. 
A question that has received considerable attention, but which is directly addressed by few scientific studies, is how many remote robots a single human can manage. In general, the answer is dependent on factors such as the level of autonomy of the robot (e.g., teleoperation requires a great deal of direct attention from the human), the task (which defines not only the type and quantity of data being returned to the human but also the amount of attention and cognitive load required of the human), and the available modes of communication.

In the search and rescue domain, Murphy [197] asserts that the demands of the task, the form factor of the robot, and the need to protect robot operators requires at least two operators, an observation that has received strong support from field trials using mature technologies [45], and partial support in search and rescue competitions using less mature but more ambitious technologies [264]. In other domains, some assert that, given sophisticated enough autonomy and possibly coordinated control, it is possible for a single human to manage more than one robotic asset $[187,190]$ though the task may still need another human to interpret sensor information. Still others assert that this problem is ill-formed when robots are used primarily as an information-gathering tool [121]. An intermediate position is that the right question should not focus on how many robots can be managed by a single human, but rather the following: how many humans does it take to efficiently manage a fixed number of robots, allowing for the possibility of adaptable autonomy and dynamic handoffs between humans [266].

One measure that has received some attention in the literature is the notion of fan-out, which represents an upper bound on the number of independent, homogeneous robots that a single person can manage $[216,217]$. This measure is supported by a limited set of techniques for estimating it [68]. Some work has been done to refine the fan-out to apply to teams of heterogeneous robots [112] and to tighten the bound by identifying various aspects of interaction [190]. In its present form, however, it is clear that fan-out is only a designer guideline and is insufficient, for example, to provide a trigger strategy [144] for adaptive automation. Alternatives to fan-out include predicting the performance of a team of heterogeneous robots from measurements of neglect tolerance and interaction times [69]. 
In addition to the number of humans and robots in a team, a key problem is the organization of the team [98, 213]. One important organizational question is who has the authority to make certain decisions: robot, interface software, or human? Another important question is who has the authority to issue instructions or commands to the robot and at what level: strategic, tactical, or operational? A third important question is how conflicts are resolved, especially when robots are placed in peer-like relationships with multiple humans. A fourth question is how roles are defined and supported: is the robot a peer, an assistant, or a slave; does it report to another robot, to a human, or is it fully independent?

Spanning all of these questions is whether the organizational structure is static or dynamic, with changes in responsibilities, authorities, and roles. In one study, managing multiple robots in a search and rescue domain under either manual or coordinated control produced results that strongly favored coordinated control [308]. In another study, four autonomy configurations, including two variations of sliding autonomy, were managed by a human working on a construction task with a team of heterogeneous robots [266]. In this study, the tradeoffs between time to completion, quality of behavior, and operator workload were strongly evident. This result emphasizes the importance of using dynamic autonomy when the world is complex and varies over time. In a third study, researchers explored how making coordination between robots explicit can reduce failures and improve consistency, in contrast to traditional interfaces [147]. In a fourth study, researchers explored the minimal amount of gestural information required to command various formations to a team of robots [277].

In many existing and envisioned problems, HRI will include not only humans and robots interacting with each other, but also coordinating with software agents. The most simple form of this is a three-agent problem which occurs when an intelligent interface is the intermediary between a human and a remote robot [249]. In this problem, the interface agent can monitor and categorize human behavior, monitor and detect problems with the robot, and support the human when workload levels, environment conditions, and robot capabilities change. A more complicated form of this teaming is in anticipated NASA applications 
where multiple distributed humans will interact with robots and with software agents that coordinate mission plans, human activities, and system resources [29].

A final issue that is starting to gain attention is the role of the human [262]. While much of the discussion up to this point is with respect to humans and robots performing a task together, there are cases where the robot may have to interact with bystanders or with people who are not expecting to work with a robot. Examples include the urban search and rescue robot that comes across a human to be rescued, a military robot in an urban environment that must interact with civilians, and a health assistant robot that must help a patient and interact with visitors. The role of the robot with respect to humans must be taken into account. The role of the human will be discussed in more detail in Section 5.

\subsection{Adaptation, Learning, and Training}

Although robot adaptation and learning have been addressed by many researchers, training of humans appears to have received comparatively little attention in the HRI literature, even though this area is very important. One reason for this apparent trend is that an often unstated goal of HRI is to produce systems that do not require significant training. This may be because many robot systems are designed to be used in very specific domains for brief periods of times [271, 292]. Moreover, robot learning and adaptation are often treated as useful in behavior design and in task-specific learning, though adaptation is certainly a key element of long-term interactions between humans and robots [104].

On one hand, it is important to minimize the amount of human training and adaptation required to interact with robots that are used in therapeutic or educational roles for children, autistic individuals, or mentally challenged individuals. On the other hand, it is important that HRI include proper training for problems that include, for example, handling hazardous materials; similarly the very nature of using robots in therapeutic and educational roles requires that humans should directly adapt and learn from the interaction [148]. In this section, we discuss not only HRI domains that require minimum operator training, 
but also domains that require careful training. We also discuss efforts aimed to train HRI scientists and designers, and then conclude with a discussion of how the concept of training can be used to help robots evolve new skills in new application domains.

Minimizing Operator Training. Minimizing training appears to be an implicit goal for "edutainment" robots, which include robots designed for use in classrooms and museums, for personal entertainment, and for home use. These robots are typically designed to be manageable by a wide variety of humans, and training can range from instruction manuals, instruction from a researcher, or instructions from the robot itself $[210,275]$. One relevant study explored how ROOMBA robots are used in practice without attempting to make operators use the robots in a specific way [99]. Such studies are important because they can be used to create training materials that guide expectations and alert humans to possible dangers. Other such studies include those that explore how children use education robots in classroom settings [148], investigate how disabled children interact with robots in social settings [23], support humans in the house [302], and identify interaction patterns with museum guide robots [210].

Complementing such studies are efforts to use archetype patterns of behavior and well-known metaphors that trigger correct mental models of robot operation. Examples include the often stated hypotheses that people with "gaming experience" will be able to interact better (in some sense) with mobile robots than those with limited experiences in games [241]. We are not aware of any studies that directly support this hypothesis, but if it is true then it would seem to suggest that people with experiences in video-conferencing, instant-messaging, and other computer-mediated forms of communication might more naturally interact with robots. Whether this hypothesis is true is a matter of future work, but it is almost certainly true that such experiences help people form mental models that influence interactions [238]. Designers are seeking (a) to identify interaction modes that invoke commonly held mental models [66] such as those invoked by anthropomorphic robots [156] or (b) to exploit fundamental cognitive, social, and emotional processes [32]. One possible caution for these efforts is that robots may 
reach an "uncanny valley" where expectations evoked by the robot fall short of actual behavior producing an interaction that can feel strangely uncomfortable to humans $[71,194]$. However, this uncanny valley theory is unproven although researchers are now trying to experimentally verify its existence [179].

Efforts to Train Humans. In contrast to the goal of minimizing training in edutainment robots, some application domains involving remote robots require careful training because operator workload or risk is so high. Important examples of such training are found in military and police applications, space applications, and in search and rescue applications. Training for military and police applications is typified by "bomb squad" robots, training for space applications is typified by telemanipulation tasks [234], and training for military and civilian search and rescue is typified by reconnaissance using small, "human-packable robots" [85]. In both the military and search application domains, training efforts exist for both air and ground robots, and these efforts tend to emphasize the use of mobile robots in a mission context [87]. Training efforts include instructions on using the interface, interpreting video, controlling the robot, coordinating with other members of the team, and staying safe while operating the robot in a hostile environment. Such training is often given to people who are already experts in their fields (such as in search and rescue), but is also given to people who may be relatively inexperienced. In the military, police and space domains, training programs may be complemented by selection criteria to help determine which indviduals are likely to be better (in some sense) at managing a robot [79]. Selection appears to have received more attention in air robots than ground robots.

By contrast to interactions with remote robots, many applications involving proximate robots are designed to produce learning or behavioral responses with humans. Therapeutic and social robots are designed to change, educate, or train people, especially in long-term interactions [148, 245, 312]. People also adapt to service robots over the long-term and over a wide range of tasks [115], and there is growing evidence that many long-term interactions require mutual adaptation including with human bystanders $[75,131,117]$. Importantly, culture 
appears to influence both long-term and short-term adaptation, at least as far as accepting interactions with a robot [18, 94, 127, 150, 270, 306].

Training Designers. Importantly, an often overlooked area is the training of HRI researchers and designers in the procedures and practices of those whom they seek to help. Important examples of training researchers include Murphy's workshops on search and rescue robotics [198], tutorials and workshops on methodologies for understanding a work-practice domain and field studies [58], tutorials for young researchers on search and rescue [239, 240], and tutorials and workshops on metrics or experiment design for robot applications [294].

Training Robots. It is tempting to restrict training to the education of the human side of HRI, but this would be a mistake given current HRI research. In HRI, robots are also learning, both offline as part of the design process $[37,207]$ and online as part of interaction, especially long-term interaction $[89,251]$. Such learning includes improving perceptual capabilities through efficient communication between humans and robots [33, 89, 251,330], improving reasoning and planning capabilities through interaction [295, 34], and improving autonomous capabilities [258]. Approaches to robot learning include teaching or programming by demonstration [13, 55, 76, 77, 146, 218], task learning [34, 251, 207], and skill learning including social, cognitive, and locomotion skills [11, 22, 202, 233, 295]. Some researchers are exploring biologically inspired learning models, including how teaching among humans or social animals can be used to train a robot [11, 257]; others are exploring how learning can become more efficient if it leverages information about how the human brain learns in very few trials [100].

Interestingly, it can be argued that providing support for efficient programming or knowledge management systems is an important aspect of training robots in HRI [120, 327]. Additionally, it can be argued that sensitizing a robot to issues of culture and etiquette allows them to adapt to slowly changing human norms of behavior $[141,215,252]$. 


\subsection{Task-Shaping}

Robotic technology is introduced to a domain either to allow a human to do a task that they could not do before, or to make the task easier or more pleasant for the human. Implicit in this assertion is the fact that introducing technology fundamentally changes the way that humans do the task. Task-shaping is a term that emphasizes the importance of considering how the task should be done and will be done when new technology is introduced. Compared to the other ways that a designer can shape HRI, there is little written about task-shaping.

There are formal processes for understanding how the task should be done and is currently done. These processes include goal-directed task analyses, cognitive work analyses, and ethnographic studies [58, $88,301]$. Although frequently used to specify how a task is done and how it should be done, it is imperative to consider how the task will be done, including unintended consequences of design [14, 212].

One reason that little is written about task-shaping is because designers are implicitly trying to create technology and interactions that accomplish some task or function. Indeed, Woods has persuasively argued that designing a system is equivalent to making a hypothesis about how the artifact will positively shape the experience [319]. Nevertheless, it is important to consider how the task might be modified to better support interaction. Examples of explicit task-shaping include designing space or underwater equipment and tools so that handles and connectors can be manipulated by a robotic arm, "pre-cleaning" a room so that a robot vacuum can accomplish its task most efficiently [99], and performing pre-inspection tasks used to form maps and plans that can be executed by a robot.

\subsection{Finding a Unifying Theme}

There are multiple ways to frame HRI as a field. One approach is to treat HRI as a resurgent emphasis and extension of previous work in human factors, teleoperation, and supervisory control. Another approach to framing HRI is to view it as a new field that includes a con- 
vergence of previous work with new research problems caused by some new capability that fundamentally changes the problem. We assert that robot autonomy has reached the point where mixed-initiative interaction and semi-autonomous control have fundamentally changed the field from previous research on related problems. Thus, we treat HRI as a new field that faces opportunities and problems which are not simple extensions of previous work. We acknowledge, however, that it is possible to make persuasive arguments that HRI is simply a refocusing of previous efforts rather than a new field.

One way to unify the scope of current HRI research is to condense the five dimensions of designer influence into a single concept as exemplified in our proposed scale of interaction, Figure 4.2 , with the caveat that this single concept cannot capture every nuance and possible design of every HRI problem. The concept of dynamic interaction seems to capture the current research direction of many HRI efforts.

Dynamic interaction includes time- and task-varying changes in autonomy, information exchange, team organization and authority, and training. It applies to both remote and proximate interactions, including social and physical interactions. By including variable autonomy assignments, the concept of dynamic interaction subsumes adaptive and dynamic autonomy as a special case $[80,96,97,111,144$, 165, 259]. By including information exchange, dynamic interaction includes adaptive and adaptable interfaces [144, 153, 221]. By including team organization and authority, mixed initiative interaction [43, $98,162,226]$ is addressed. By including training, interactive learning is included.

More importantly, the concept of dynamic interaction places the emphasis on shaping the types of interactions that can and will emerge as humans and robots interact. The scope of HRI research and design, therefore, includes all efforts at evaluating systems and interaction paradigms, designing autonomy algorithms in the context of HRI, designing interfaces and information exchange protocols, defining and switching roles, and influencing learning and training. This emphasis on dynamic interaction differs sharply from the historically static interactions of pure teleoperation and pure supervisory control. 
Note that some current research efforts and methods do not naturally fit into the dynamic interaction framework. These include several aspects of task shaping, including ethnographic studies, goal-directed task analyses, and some cognitive science-based work. However, understanding existing processes and potential use patterns helps researchers better understand the fluid interaction patterns that are likely to exist in practice so that they can design interactions that support, improve, and extend these interaction patterns. 


\section{Problem Domains in HRI}

We have already mentioned several of the problem domains and application areas in modern HRI. In this section, we elaborate on many of these problem domains to present a survey of the kinds of problems encountered in HRI. Importantly, many of these problems have broad social impact; thus, much work in HRI uses science and engineering to respond to needs in society.

Scholtz provided a taxonomy of roles that robots can assume in HRI [262]:

- Supervisor,

- Operator,

- Mechanic,

- Peer, and

- Bystander.

To this list, we add the following:

- Mentor: the robot is in a teaching or leadership role for the human, and 
- Information Consumer: the human does not control the robot, but the human uses information coming from the robot in, for example, a reconnaissance task.

Similar taxonomies are certainly possible, but identifying how people perceive a robot's role has important ramifications for how they interact with the robot [74]. Using Scholtz's taxonomy provides insight into the current and future interactions in these applications. Table 5.1 classifies the most frequent types of interactions for the application areas discussed in the remainder of this section. For many of these areas, current research patterns exhibit a trend away from remote interactions

Table 5.1 Examples of roles and proximity patterns that arise in several application areas.

\begin{tabular}{|c|c|c|c|}
\hline Application area & $\begin{array}{c}\text { Remote/ } \\
\text { Proximate }\end{array}$ & Role & Example \\
\hline \multirow[t]{2}{*}{ Search and rescue } & Remote & $\begin{array}{l}\text { Human is supervisor or } \\
\text { operator }\end{array}$ & $\begin{array}{l}\text { Remotely operated search } \\
\text { robots }\end{array}$ \\
\hline & Proximate & $\begin{array}{l}\text { Human and robot are } \\
\text { peers }\end{array}$ & $\begin{array}{l}\text { Robot supports unstable } \\
\text { structures }\end{array}$ \\
\hline \multirow[t]{2}{*}{ Assistive robotics } & Proximate & $\begin{array}{l}\text { Human and robot are } \\
\text { peers, or robot is tool }\end{array}$ & $\begin{array}{l}\text { Assistance for the blind, } \\
\text { and therapy for the } \\
\text { elderly }\end{array}$ \\
\hline & Proximate & Robot is mentor & $\begin{array}{l}\text { Social interaction for } \\
\text { autistic children }\end{array}$ \\
\hline \multirow[t]{3}{*}{ Military and police } & Remote & Human is supervisor & $\begin{array}{l}\text { Reconnaissance, } \\
\text { de-mining }\end{array}$ \\
\hline & $\begin{array}{l}\text { Remote or } \\
\text { Proximate }\end{array}$ & $\begin{array}{l}\text { Human and robot are } \\
\text { peers }\end{array}$ & Patrol support \\
\hline & Remote & $\begin{array}{l}\text { Human is information } \\
\text { consumer }\end{array}$ & $\begin{array}{l}\text { Commander using } \\
\text { reconnaissance } \\
\text { information }\end{array}$ \\
\hline \multirow[t]{3}{*}{ Edutainment } & Proximate & Robot is mentor & $\begin{array}{l}\text { Robotic classroom } \\
\text { assistant }\end{array}$ \\
\hline & & Robot is mentor & $\begin{array}{l}\text { Robotic museum tour } \\
\text { guide }\end{array}$ \\
\hline & & Robot is peer & Social companion \\
\hline \multirow[t]{2}{*}{ Space } & Remote & $\begin{array}{l}\text { Human is supervisor or } \\
\text { operator }\end{array}$ & $\begin{array}{l}\text { Remote science and } \\
\text { exploration }\end{array}$ \\
\hline & Proximate & $\begin{array}{l}\text { Human and robot are } \\
\text { peers }\end{array}$ & $\begin{array}{l}\text { Robotic astronaut } \\
\text { assistant }\end{array}$ \\
\hline \multirow[t]{3}{*}{ Home and industry } & Proximate & $\begin{array}{l}\text { Human and robot are } \\
\text { peers }\end{array}$ & Robotic companion \\
\hline & Proximate & Human is supervisor & Robotic vacuum \\
\hline & Remote & Human is supervisor & Robot construction \\
\hline
\end{tabular}


toward proximate interactions, and away from operator roles toward peer or mentor roles.

\subsection{Search and Rescue}

The highest profile HRI research area in the United States is a strong example of work with important social impact. This area is urban search and rescue (USAR), and is exemplified by the use of robots in rescue and recovery efforts after the collapse of the World Trade Center buildings [51]. Lead by pioneering government and academic efforts [26, 200], USAR has grown into one of the most important areas of HRI.

Because of its importance, USAR has become an HRI challenge problem. As such, there have been efforts to provide standardized USAR test areas and performance measures, and to standardize robot-assisted USAR efforts $[138,199,263]$. There are regular USAR competitions at robot-related conferences [159, 199, 325]. A wide variety of interface concepts, autonomy designs, sensor-processing algorithms, robot morphologies, field studies, and human factors analyses and experiments have been created in the name of robot-assisted USAR (see, for example, [197, 198, 211, 264, 318]). Recently, these efforts are being extended from ground robots to include aerial robots used in natural disaster and wilderness search [61, 278].

\subsection{Assistive and Educational Robotics}

In the spirit of socially relevant research, robots are being developed to serve in assistive and educational capacities. Assistive robotics is perhaps one of the highest profile areas of HRI in the world. This application domain often places the robot in a peer-like or mentoring role with the human in practice, even though the intention of the robot is designed to provide service to the human. For example, robots being developed to assist the visually challenged work in close proximity to humans and must merit an appropriate level of trust. The goal of work in this area is to increase the set of tasks that a visually impaired person can independently perform. These tasks include providing naviga- 
tion assistance in unstructured domains [167, 170, 274], and providing information about locations (and prices) in grocery stores and transportation facilities [168].

Another important area of research, especially in countries with a burgeoning population of the elderly, is providing support for those who have age-related challenges [192, 231, 232, 252, 304]. Researchers in this area focus on both physical needs such as mobility assistance [324], emotional welfare [252, 303], and cognitive assistance [151]. Many working in this area are fully aware of the ethical considerations that arise by delegating a companionship role to a robot and the trust issues that arise by having an artificial agent working with someone with mental challenges such a senility [286]. Having the ability to remotely manage a personal assistant robot over the internet may be a step in the direction of addressing these ethical concerns, though substantial technological and privacy limitations exist for such interaction [166].

For some people with physical and mental challenges, robots may provide an opportunity for interaction and therapy. Such work is being explored with autistic children [23, 247]. Many of these children respond weakly or not at all to social cues, but respond well to mechanical devices. Robots provide a possible therapeutic role for using a mechanical device to improve social interactions [312]. Robots are also being considered for other domains where children are benefited, such as those who have experienced trauma. Importantly, the social dimension of HRI is considered necessary not only in assistive roles but also in many areas of proximate interaction [31, 32, 72, 90, 106, 148]. Indeed, the area of social robotics is so large that it is already time to update the highly cited 2003 survey [94].

For some people with physical challenges, the embodiment of a robot provides unique opportunities not available in other forms of technology. For example, researchers are working on designing robots that provide support for physical therapy. Efforts include providing prescribed force and movement trajectories to help rebuild flexibility and strength [178]. Other work includes detecting motivational state and adjusting therapy to maximize benefits [236]. Intelligent wheelchairs are a type of robot that uses external sensors to support path planning, collision avoidance, etc. for a person that requires a wheelchair [134, 324]. 
Physical interaction with robots is not limited to providing assistance to those with some form of disability. Many robot architectures have been designed to assist humans in industrial settings [228]. Indeed, developing telerobots for use in hazardous materials handling has been ongoing for several decades [139]. However, cooperative systems are not limited to large-scale industrial settings, but may be most useful in small-scale tasks "such as microassembly and microsurgery" [180]. The technologies developed for such assistive support appear to apply not only to proximate physical interaction, but also to the general telemanipulation problem [224].

In the spirit of providing assistance to those without a disability, some researchers are also exploring how robots can be used to promote education for typical children, both in the home and in schools $[62,140]$. The personal service robot is an extension to the theme of providing service to the general population. Indeed, South Korea has ambitious goals about the advancement of such robots [219].

\subsection{Entertainment}

Although there have been many examples of entertainment robotics, from an HRI perspective, not much has been published in the literature. Early entertainment robotics centered on animatronics, where the robot generally plays prerecorded sounds that are synchronized with the robots motion. These types of robots can often be found in old movies and theme parks; however, the interaction is mostly in one direction, that of the robot presenting information, although the robot's performance may be triggered by the presence of the human. However, the 2005 AICHI Expo demonstrated several robots designed to entertain, including the use of robots as actors and dance partners [6]; similar work on the relationship between acting, drama, and artificial agents is presented in [41]. Here again, the role of the human is as an observer, and the interaction is minimal and more implicit [41].

The Valerie and Tank robots at Carnegie Mellon University were designed as robot receptionists as a joint project between CMU's Robotics Institute and the School of Drama [106]. The robots have a rich back story and strive to increase users' interaction by encouraging 
the user to ask about the robots' lives outside of their role as receptionists. Although robots that act as tour guides might be considered a form of assistive robotics, we classify such robots under the category of entertainment because their primary role is to engage participants $[120,210]$.

Although not strictly entertainment, the Insect Telepresence project [8] placed Madagascar Hissing Cockroaches in a terrarium, and allowed users, through mediated telepresence, to drive a miniature camera within the terrarium, at eye level to the cockroaches. The image from the camera was projected much larger than life on a wall. Of interest was the mediated teleoperation, which limited the accelerations of the camera motions to below that which would cause the cockroaches to react to the camera, offering the humans a look into the cockroach's world.

Other HRI-related research in the use of robots for entertainment include robotic story tellers [191], robotic dance partners [163], robotic plants that give users information such as incoming email [137], and robotic pets [94, 272].

\subsection{Military and Police}

Many have called for robots to be used in tasks that are "dull, dirty, or dangerous." Military and police applications often simultaneously satisfy all three criteria for robot use. Applications include gathering information to support a dangerous task such as a SWAT team takedown, or using remote vehicles in combat to minimize risk exposure to soldiers. Current work emphasizes robots as servants to soldiers and officers [87], typically in remote operations, but efforts to have robots work in a peer-like role are underway $[44,155]$.

A typical use of robots in both military and police applications is in bomb disposal (called "improvised explosive devices" in many military situations) [263]. Remotely controlled robots are frequently used to approach and evaluate suspicious packages [311]. Controlling these robots is demanding on the operators, especially since many current interfaces and autonomy levels require operators to integrate information from multiple sources of data such as multiple cameras. In addition 
to controlling mobile platforms, telemanipulation is an important part of such work. Robot arms are often mounted on the platforms providing operators some ability to manipulate the object. Because of the limited situation awareness for controlling these arms, some researchers are exploring sensor technologies and information presentation techniques that improve awareness in telemanipulation [242].

\subsection{Space Exploration}

Robots have long been part of space exploration. In fact, according to some definitions, a satellite can be considered a type of robot, albeit one that has a high degree of autonomy and typically requires minimal intervention.

As has been previously noted, remarkable success in space robotics include the Soviet Lunokhods which were used to explore the surface of the moon [95] followed by more recent NASA success in exploring the surface of Mars $[174,317]$. It is anticipated that the robots will continue to have a strong role in envisioned and future explorations of the lunar and Martian surfaces, in construction tasks on these surfaces as well as in the international space station, and in remote science and maintenance tasks [84, 129, 177, 225].

Many precursor and early human missions will depend heavily on remotely managed robots, but will also likely include extravehicular activities. To prepare for these missions, NASA and other international space agencies engage in frequent field work designed to evaluate both the robotic and HRI technologies. Examples of this include development of the Dante robots [16, 17], a series of Extra-Vehicular Activ-

ities (EVA)-based field tests [47, 114, 296], and field tests involving substantial communications delays and remote science in harsh environments $[283,310]$. Research that extends these efforts includes the aforementioned Robonaut development and work on developing intelligent rovers and robot "mules" to pack astronaut equipment on long duration EVAs.

Complementing the focus on remote and EVA-based interaction are efforts to support astronauts at the international space station and on long duration space missions. These efforts focus on astronaut 
assistants and small satellites [54, 81]. Many of the NASA programs include strong planning components and seek to integrate software, robotic, and human agents [30]. Other work calls for standardization of robot parts, procedures, communications, and interfaces [91, 92].

\subsection{UAV Reconnaissance and UUV Applications}

Unmanned Air Vehicles are rapidly attracting attention as an application area for HRI and for aviation technology. UAVs have been around for a long time and have a large body of related literature, but the label for such vehicles varies over time. Among other labels, UAV work has been published under names like remotely piloted vehicles, uninhabited air vehicles, autonomous micro air vehicles, and autonomous aerial systems. The key defining aspect of UAV interaction is the fact that the vehicles are, by definition, remotely operated, move in three dimensions, and typically have six degrees of freedom. Interestingly, remote interactions and a high degree of freedom are also defining attributes for problems that use Unmanned Underwater Vehicles (UUVs), often referred to as autonomous underwater vehicles. Because of this similarity, we unite our discussion of these two important areas of HRI. This unification may be particularly relevant because the literature from these two communities rarely overlaps even though the interaction dynamics have marked similarities.

In addition to the previously mentioned reconnaissance-based military and search-and-rescue uses of UAVs, there are a number of other envisioned uses of these vehicles. These include atmospheric science [107], landing site surveillance of a Mars rover [19], border patrol [103], pollution monitoring [113], forest fire monitoring [49], infrastructure inspection [113], and munitions-based military applications [70]. UUVs have similarly broad areas of use. They include undersea science, treasure hunting, undersea and surf-zone de-mining, and underwater construction and maintenance [329]. For remote operations, there are many interface designs that apply to both UAV and UUV operations. These include integrating multiple perspectives, developing a sense of telepresence, synchronizing frames of reference through tethers, and building mosaics [101, 230]. 


\subsection{Other Applications}

There are a host of other application domains where robots are used. These domains include home use, manufacturing, inventory management, mining, and precision agriculture. Importantly, some of these application domains include strong HRI research, but others attempt the creation of "fully autonomous" robots that do not require human interaction and, ironically, are not "autonomous enough" to allow interaction with humans. Although it is possible that some of these domains might allow "fire-up and forget" robots, it is likely that the usefulness and safety of robots in many of these domains will increase if HRI considerations are included in their design. 


\section{6}

\section{Solution Themes, Scientific Approaches, and Challenge Problems}

One measure of the maturity of a research field is the emergence of a series of accepted practices and challenge problems that focus the attention of the field. Equally important is the identification of solution themes that cross applications. In this section, we survey several practices, challenge problems, and solution themes.

\subsection{Accepted Practices}

There are a number of accepted practices that are emerging in HRI. A key practice is to include experts from multiple disciplines on research efforts. These disciplines frequently include robotics, electrical and mechanical engineering, computer science, human-computer interaction, cognitive science, and human factors engineering. Other relevant disciplines include design, organizational behavior, and the social sciences. Importantly, some conferences encourage multidisciplinary submissions are working to establish the practice of having all papers refereed by reviewers representing different disciplines [265].

A second emerging practice is to create real systems (robot autonomy, interaction modes, and etc.) and then evaluate these systems 
using experiments with human subjects. Proof-of-concept technologies, although important, are less valuable than they would be if they were supported by careful experiments that identify key attributes of the design or principles that span applications. Identification of descriptive interaction phenomena is interesting, but elaboration on the psychological principles underlying these phenomena with an eye toward harnessing these principles in design is more useful. Thus, engineering, evaluation, and modeling are key aspects of HRI.

A third emerging practice is conducting experiments that include a careful blending of results from simulated and physical robots. On the one hand, because of cost and reliability issues, it is often difficult to conduct carefully controlled experiments with physical robots. On the other hand, it is often difficult to replicate simulation-only results with physical robots because the physical world presents challenges and details that are not present in many simulations. It is common to "embody" at least one portion of the interaction, be it a physical robot, some physical sensor, or real-world speech. Some research includes work using carefully controlled simulation environments and replication of selected results with physical robots. Others use wizard of $\mathrm{Oz}$ studies. Others form communities where roboticists design technologies and where other human factors researchers collect and analyze results from tests; this is the operating structure of part of the robotassisted urban search and rescue (USAR) community [325]. Interestingly, at least one research group is exploring how a simulated user can help support the design of human-robot interfaces [244].

A fourth area of emerging effort is establishing standards and common metrics. The most complete survey of metrics is in [280], but much work on metrics exists in the literature including the proceedings of the annual PERMIS workshops. Standardization efforts have been strongest in the USAR domain $[138,199]$, but are also present in space applications and UAVs [91, 92].

A fifth emerging practice is the use of longitudinal studies. Such studies, which can last from several weeks to several months, require a considerable investment by researchers, both in terms of hours and financial resources. One reason that long-term studies are a relatively recent practice is that many robots were not reliable enough 
to work over the study period. The availability of reliable personal home robots and service robots in public areas has made such studies possible [99, 120]. The European COGNIRON project is a good example of a commitment to long-term studies [59]. Longterm studies shift research methodologies from carefully controlled small-scale experiments to other methodologies such as surveys and ethnography.

\subsection{Challenge Problems}

It is often useful to identify a set of challenge problems that focus the efforts of a community. HRI has a suite of challenge problems, some explicitly identified as such and others implicitly operating as such. In this section, we identify a collection of problems that are likely to shape HRI in the near future. For each problem, we discuss those aspects of the problem that make it particularly challenging and useful.

USAR is the most high profile of the HRI challenge problems. The attributes that define this as a challenge problem include the highly unstructured nature of USAR environments. This imposes strict challenges on robot mobility, communications, map-building, and situation awareness.

Developing robots to be used in military reconnaissance and combat is another high profile challenge area in HRI. Similar to USAR, environments tend to be unstructured, but perhaps more importantly operators may be required to operate under extreme stress in the presence of an adversary that is trying to prevent their success.

Space robotics is another area where the environment is often unstructured, and the environment is often extreme in terms of temperature, radiation, the vacuum of space, and the presence of dust. Important characteristics of space robotics include the observation that operators can be highly trained, but communications may be very limited due to time delays, power limitations, and even operator mobility (as in the case of an astronaut interacting from within a space suit).

Assistive robotics is a challenge area, but not because the environment is unstructured per se. Rather, the key attributes of this problem 
are the proximity and vulnerability of the human in the interaction plus the potential for interactions that may evolve in unanticipated patterns.

Humanoid robotics is a challenge area, both in terms of engineering human-like movements and expressions, and in terms of the challenges that arise when a robot takes a human form. With such a form, social and emotional aspects of interaction become paramount.

Natural language interaction is a challenge problem, not only because it requires sophisticated speech recognition and language understanding, but also because it inevitably includes issues of mixedinitiative interaction, multi-modal interaction, and cognitive modeling.

\subsection{Solution Themes}

HRI presents a number of problems that cross application domains. These problems include requirements on autonomy, information sharing, and evaluation. Emerging from these problems are a set of solution themes that cross applications and that, when addressed, can be leveraged across several problems. In this section, we identify some of these solution themes and discuss some of the open questions associated with them.

Dynamic Autonomy, Mixed-Initiative Interaction, and Dialog. Because most interesting applications of human-robot interaction include rich information exchanges in dynamic and complex environments, it is imperative that interactions and resulting behaviors can accommodate complexity.

Telepresence and Information Fusion in Remote Interaction. Although remote control and teleoperation are the oldest forms of human-robot interaction, the problem is far from solved. In fact, with advances in robot morphology, sensor processing, and communications, it is necessary to find new ways to fuse information to provide humans an operational presence with the robot. Obstacles to achieving this include bandwidth limitations, communications delays and drop-outs, mismatches in frames of reference, communicating intent and trusting autonomy, and mismatches between expectations and behaviors. 
Cognitive Modeling. Effective interactions between humans include a common ground created by common experiences and cultures. This common ground creates realistic expectations and forms the basis communications. From a robot's perspective, supporting effective interactions also requires establishing and maintaining common ground. An emerging approach to doing this is to create cognitive models of human reasoning and behavior selection. The goal is to create rich enough models either (a) to allow the robot to identify a human's cognitive state and adjust information exchange accordingly or (b) to allow the robot's behavior to be generated by models that are interpretable by a human.

Team Organizations and Dynamics. Many HRI researchers are striving to develop systems that allow multiple robots and multiple humans to interact with each other. To accomplish this, it is necessary to shape team interactions and dynamics by establishing organizational structures, communications protocols, and support tools. Team organizations necessarily subsume different and dynamic roles, which implies that such efforts will need to leverage lessons from research on mixed initiative and dialog.

Interactive Learning. Because the world is complex, interactions between humans and robots are also complex. This implies that it is impossible to anticipate every conceivable problem and generate scripted responses, or anticipate every conceivable percept and generate sensor processing algorithms. Interactive learning is the process by which a robot and a human work together to incrementally improve perceptual ability, autonomy, and interaction. 


\section{Relation to Other Fields}

Although we have framed HRI as a new field in this review, HRI has strong ties to previous and ongoing work in telerobotics, intelligent vehicle systems, human-computer interaction, etc. In this section, we review many of the stronger ties to these fields. We begin with the most relevant: telerobotics and supervisory control.

\subsection{Telerobotics and Teleoperation}

Sheridan's papers and books on telerobotics and supervisory control are perhaps the most influential in the field. In 1992, his book outlined the state of the art in human-robot interaction, with an emphasis on open problems, mathematical models, and information flow [267]. This book was followed by a 2002 updated survey and framework of human factors for the general human-machine interaction problem [268].

Even more influential than his books, perhaps, is Sheridan's and Verplank's levels of automation in human-machine interaction. These 10 levels of automation span the range from direct control through decision support to supervisory control [269]. More recently, Parasuraman and Wickens teamed with Sheridan to extend these 10 levels of automation beyond decision support to other aspects of human-machine 
interaction [248]. Levels of automation foreshadow more recent concepts of dynamic autonomy in all its forms [67, 144].

In addition to these seminal works, there are numerous examples of remote robot operation. One example comes from attempts during World War II to remotely control aircraft. This lead to the study of remotely piloted vehicles [95], a precursor of more modern work on the Human Factors of Unmanned/Uninhabited Aerial Vehicles [322].

Complementing the work on remotely piloted aircraft is a work on unmanned underwater vehicles (UUVs). This work includes both military and scientific applications, and spans topics of remote visualization, telepresence, and information display [329].

\subsection{Human Factors and Automation Science}

The field of human factors emerged as the confluence of engineering psychology, ergonomics, and accident analysis. Human factors work relevant to HRI includes important lessons from thought provoking papers such as Bainbridge's "Ironies of Automation" [14] and Hancock's position paper on the make-up of HRI teams [121]. Human factors work is motivated by numerous stories, sometimes humorous and sometimes sobering, from years of humans interacting with automation in various forms [50].

The human factors literature has produced key concepts of interaction, such as mental workload [110, 204], situation awareness [88], mental models $[142,300]$, and trust in automation [173]. It also includes several themes, frameworks, and models that provide a solid foundation for describing and predicting responses to human-robot interaction. These contributions include the seminal work of Rasmussen who presented a hierarchy of interaction that included knowledge-based, rule-based, and skill-based interactions [237]. Rasmussen's hierarchy is a human factors complement to hierarchical and intelligent control [7, 183, 255]. Contributions also include general principles of cognitive ergonomics, with particularly powerful ideas such as Wickens's Multiple Resource Theory [314]. Complementing these models are interaction phenomena that are common enough that they are elevated to the status of law by David Woods [320]. 
Rich as these models and laws are, they cannot substitute for practical real-world observation. This point was strongly made by Hutchins in the book "Cognition in the Wild" [130]. In the spirit of real-world observation, the field of ethnography has developed a set of methodologies for recording observations in real-world settings, and some ethnographers have tried to translate these observation and summarization methods into tools for designing interventions [57, 58, 93].

Growing out of the need to understand the goals, tasks, and information flow of existing processes, a series of methodologies have emerged that produce formalized models for how "things get done." These methodologies include Goal-Directed Task Analysis, Cognitive Task Analysis, and Cognitive Work Analysis [88, 301]. These methodologies produce models of goals, tasks, and information flow, which are being used in HRI [4]. Complementing these high-level models are cognitive models of the mental processes used to accomplish tasks, and activity analyses of existing work practices. The cognitive models and activity analyses are especially interesting to HRI because they can be used not only as models of existing processes, but also as tools to generate behaviors such as perspective-taking and planning [295].

It is worth noting that cognitive psychology and social psychology offer perspectives and insights that are distinct from traditional human factors. There is a trend in HRI to include cognitive and social scientists in collaborative research efforts with roboticists, human factors engineers, and experts in human-computer interaction.

Given the rich history of human factors and the recent emergence of HRI, it is unfortunate and perhaps inevitable that some relevant human factors work is called by different names in the different fields. Examples include adjustable autonomy and Inagaki's Situation-Adaptive Autonomy [132, 133]; and augmented reality/virtuality and synthetic vision [48].

\subsection{Aviation and Air Traffic Control}

Modern aircraft are among the most capable semi-autonomous systems in use. Moreover, because of the safety critical nature of aviation, aircraft systems must be extremely robust and reliable. Careful human 
factors analyses are often performed to justify a change to an aircraft system. From one perspective, an aircraft is a very capable type of robot, albeit one that happens to carry the human operator.

As a result, HRI has many lessons that it can learn from aviation, both in terms of useful technologies and careful human factors analysis. Relevant examples include ground proximity warning systems, which use multi-modal communications coupled with robust autonomy to prevent controlled flight into terrain [63]. Tunnel-in-the-sky displays can increase situation awareness by helping pilots to understand how control choices will affect the trajectory of the aircraft [195]. Problems caused by mode confusion, by the operator being out of the loop, by vigilance, by excessive workload, and by team coordination issues have all received attention and been mitigated by procedures and technologies.

As robots become more capable, an important issue is how many robots can be managed by a single human. This question makes another aspect of aviation relevant to HRI, namely, human factors work done with the air traffic control problem (ATC). ATC is a problem that involves sequencing, deconflicting, and handing off multiple highly capable systems [123]. Indeed, the autonomy level of these aircraft is extremely high, since they consist of both a trained and intelligent human operator as well as aircraft autonomy. Nevertheless, ATC imposes high workloads on operators. Careful human factors analyses have been performed and mitigating technologies have been developed $[86,214]$. Because of the safety critical nature of ATC, many potentially useful technologies have not been incorporated into ATC systems. Even so, some ATC-related research and development could serve as a type for HRI problems.

There are three other aspects of aviation and ATC that are very relevant to HRI. First, ATC training and certification programs have many desirable attributes that could be imitated in HRI. Second, because aviation incidents are relatively rare and, when they occur, can damage career prospects, the aviation industry has developed anonymous reporting procedures which are kept in a database of problems that have occurred. As HRI matures, it could be useful to create a standardized reporting system to identify and mitigate problems that frequently arise. Third, the aviation industry has a strong set of standards. There 
have been recent efforts to bring the standardization process to HRI [92], though it is important that these efforts do not impose undue restrictions on creativity and design.

\subsection{Intelligent Vehicle Systems}

The field of intelligent vehicle systems (IVS) has received considerable attention in recent decades, including the emergence of several conferences and journals $[1,2,3,288]$. The field of intelligent vehicle systems has many problems in common with HRI, including designing autonomy that supports human behavior, creating attention-management aides, supporting planning and navigation under high-workload conditions, mitigating errors, and creating useful models and metrics $[27,108,109]$. Indeed, a strong case can be made that modern automobiles are just semi-autonomous robots that carry people.

IVS not only include automobiles, but also trains, busses, semitrucks and other forms of public transit [25]. The users of IVS range from those that are highly trained to those that are untrained and sometimes even uninformed. Moreover, IVS must be designed to be safety-critical, time-critical, and to operate under high workload conditions. The presence of untrained operators and high-demand tasks produces technologies that may be relevant for those aspects of HRI that require interaction with bystanders or naïve operators.

\subsection{Human-Computer Interaction $(\mathrm{HCl})$}

As the field of HRI has grown, it has seen many contributions from researchers in HCI and it has been nurtured by HCI organizations. For example, the first International Conference on Human-Robot Interaction was sponsored by ACM's Computer-Human Interaction Special Interest Group [265]. HRI research is attractive to many members of the HCI community because of the unique challenges posed by the field. Of particular interest is the fact that robots occupy physical space. This offers unique challenges not offered in desktop metaphors or even pervasive computing. Physical location in a $3 \mathrm{D}$ space imposes strong requirements on how information is displayed in remote operation, and 
even stronger requirements on how space is shared when robots and humans occupy the same space. HRI benefits from contributions from HCI researchers, both in methodologies, design principles, and computing metaphors.

\subsection{Artificial Intelligence and Cybernetics}

Because of their emphasis on designing intelligence for human-built systems, the fields of artificial intelligence (AI) and cybernetics have a great deal of relevance to the field of HRI. Intelligence and autonomy are closely aligned. Indeed, when experimenters want to give the illusion of truly intelligent robots, it is common to use a "wizard of Oz" design wherein experiment participants believe that they are controlling an intelligent robot but where in reality the commands that they issue are received and translated into teleoperation commands by a hidden human [116].

HRI frequently uses concepts from AI in the design of autonomy algorithms. Moreover, AI techniques have informed and been informed by concepts from cognitive science. For example, the ACT-R system, a popular tool for modeling cognition, uses AI-like production rules. Such cognitive models have increasingly become relevant to HRI, both as tools for modeling how a human might interact and as the basis for generating robot behavior [295].

Although sometimes justifiably treated as a separate field from AI, augmented reality and telepresence have much relevance to HRI. Augmented reality techniques are used to support remote interactions in NASA's Robonaut [9]. Augmented virtuality and mixed reality are variations of augmented reality that have found application in HRI [208]. Some suggest that telepresence, the natural extension of human awareness of a remote space, is a goal of interface design in HRI, though others note that a feeling of remote presence is not necessary provided that information is displayed in a way that supports intentional action in the remote space [208].

Another AI-related area that has developed into a separate field of study is computer vision. Computer vision algorithms are frequently used to translate camera imagery into percepts that support autonomy. 
Moreover, these algorithms are also used to provide enhanced awareness of information through the use of image stabilization, mosaics, automated target recognition, and image enhancement.

Many AI techniques are used in computer games. These games, some of which are very sophisticated, provide a probe into the levels of autonomy needed to support useful interactions. Given these levels of autonomy, information is integrated and presented to operators in several different forms; evaluating these forms of information presentation provides guidelines for interface designers in HRI [241]. Sophisticated multi-player online games may become useful in understanding how natural language can be used to support HRI and how human-robot teams should interact.

Finally, machine learning is a subfield of AI that is proving very useful in robotics and HRI. Machine learning can be used to develop robot behaviors, robot perception, and multi-robot interaction [40, 89, 207]. Interactive learning has received attention as a way to capture and encode useful robot behaviors, to provide robot training, and to improve perception. Interactive techniques with intelligent systems are also present in AI. Interactive proof system, interactive planners, and "programming by reward" in machine learning are all examples of how human input can be used in collaboration with AI algorithms.

\subsection{Haptics and Telemanipulation}

Before concluding the review, it is important to note that much of the field of haptics and telemanipulation are aligned with the goals and challenge problems of HRI. However, the current research culture tends to treat haptics/telemanipulation separate from HRI, perhaps because of the longer history of the field of haptics. Since the two fields have much to learn from each other, it is desirable that the research communities increase interactions. 
Human-robot interaction is a growing field of research and application. The field includes many challenging problems and has the potential to produce solutions with positive social impact. Its interdisciplinary nature requires that researchers in the field understand their research within a broader context. In this survey, we have tried to present a unified treatment of HRI-related problems, identify key themes, and discuss challenge problems that are likely to shape the field in the near future. 


\section{References}

[1] Proceedings of the International Driving Symposium on Human Factors in Driver Assessment, Training and Vehicle Design.

[2] Proceedings of the IEEE Conference on Intelligent Transportation Systems.

[3] European Annual Conference on Human Decision Making and Contro.

[4] J. A. Adams, "Human-robot interaction design: Understanding user needs and requirements," in Human Factors and Ergonomics Society 49th Annual Meeting, 2005.

[5] J. A. Adams and M. Skubic, "Special issue on human-robot interaction," IEEE Transactions on Systems, Man, and Cybernetics: Part A - Systems and Humans, vol. 35, no. 4, 2005.

[6] AICHI, Robot Project: We Live in the Robot Age at EXPO 2005. Available from: http://www.expo2005.or.jp/en/robot/robot_project_00.html, 2005.

[7] J. S. Albus, "Outline for a theory of intelligence," IEEE Transactions on Systems, Man, and Cybernetics, vol. 21, no. 3, pp. 473-509, 1991.

[8] S. All and I. Norbaksh, "Insect telepresence: Using robotic tele-embodiment to bring insects face-to-face with humans," Automous Robots, Special Issue on Personal Robotics, vol. 10, pp. 149-161, 2001.

[9] R. O. Ambrose, H. Aldridge, R. S. Askew, R. R. Burridge, W. Bluethmann, M. Diftler, C. Lovchik, D. Magruder, and F. Rehnmark, "Robonaut: NASA's space humanoid," IEEE Intelligent Systems and Their Applications, vol. 15, no. 4, pp. 57-63, 2000.

[10] R. C. Arkin, Behavior-Based Robotics. Cambridge, MA, USA: The MIT Press, 1998. 
[11] M. Asada, K. F. MacDorman, H. Ishiguro, and Y. Kuniyoshi, "Cognitive developmental robotics as a new paradigm for the design of humanoid robots," Robotics and Autonomous Systems, vol. 37, no. 2-3, pp. 185-193, 2001.

[12] I. Asimov, Robot Dreams. New York: Ace Books, 1986.

[13] C. G. Atkeson and S. Schoal, "Robot learning from demonstration," in International Conference on Machine Learning, 1997.

[14] L. Bainbridge, "Ironies of automation," Automatica, vol. 19, no. 6, pp. 775$779,1983$.

[15] M. Baker, R. Casey, B. Keyes, and H. A. Yanco, "Improved interfaces for human-robot interaction in urban search and rescue," in IEEE International Conference on Systems, Man, and Cybernetics, The Hague, The Netherlands, 2004.

[16] J. Bares and D. Wettergreen, "Lessons from the development and deployment of dante II," in 1997 Field and Service Robotics Conference, Canberra, Australia, 1997.

[17] J. E. Bares and D. S. Wettergreen, "Dante II: Technical description, results, and lessons learned," The International Journal of Robotics Research, vol. 18, no. 7, pp. 621-649, 1999.

[18] C. Bartneck, T. Namura, T. Kanda, T. Suzuki, and K. Kato, "A cross-cultural study on attitudes towards robots," in HCI International, 2005.

[19] R. W. Beard, D. J. Lee, M. Quigley, S. Thakoor, and S. Zornetzer, "A new approach to observation of descent and landing of future Mars mission using bioinspired technology innovations," AIAA Journal of Aerospace Computing, Information, and Communication, vol. 2, no. 1, pp. 65-91, 2005.

[20] G. Beavers and H. Hexmoor, "Types and limits of agent autonomy," in Agents and Computational Autonomy: Potential, Risks, and Solutions, (M. Nickles, M. Rovatos, and G. Weiss, eds.), Berlin/Heidelberg: Springer, 2004.

[21] A. Billard, Robota. 2007. Available from: http://lasa.epfl.ch/research/toys/ robota/photos_videos/Fermarillo/_00014.htm.

[22] A. Billard and K. Dautenhahn, "Experiments in social robotics: Grounding and use of communication in automous agents," Adaptive Behavior, vol. 7, no. (3-4), pp. 415-438, 1999.

[23] A. Billard, B. Robins, J. Nadel, and K. Dautenhahn, "Building robota, a mini-humanoid robot for the rehabilitation of children with autism," RESNA Assistive Technology Journal, 2006.

[24] Bio-Mimetic Control Research Center, Available from: http://www.bmc. riken.jp/ RI-MAN/index_ us.html.

[25] R. Bishop, "A survey of intelligent vehicle applications worldwide," in IEEE Intelligent Vehicles Symposium, IEEE: Dearborn, MI, USA, 2000.

[26] J. G. Blitch, "Artificial intelligence technologies for robot assisted urban search and rescue," Expert Systems with Applications, vol. 11, no. 2, pp. 109-124, 1996.

[27] E. R. Boer, E. C. Hildreth, and M. A. Goodrich, "A driver model of attention management and task scheduling: Satisficing decision making with dynamic mental models," in 17th European Annual Conference on Human Decision Making and Control, Valenciennes, France, 1998. 
[28] R. P. Bonnasso, R. J. Firby, E. Gat, D. Kortencamp, D. P. Miller, and M. G. Slack, "Experiences with an architecture for intelligent, reactive agents," Journal of Experimental and Theoretical Artificial Intelligence, vol. 9, no. 2/3, pp. 237-256, 1997.

[29] J. M. Bradshaw, A. Acquisti, J. Allen, M. Breedy, L. Bunch, N. Chambers, L. Galescu, M. Goodrich, R. Jeffers, M. Johnson, H. Jung, S. Kulkarni, J. Lott, D. Olsen, M. Sierhuis, N. Suri, W. Taysom, G. Tonti, A. Uszok, and R. van Hoof, "Teamwork-centered autonomy for extended human-agent interaction in space applications," in Proceedings of the AAAI Spring Symposium: Interaction between Humans and Autonomous Systems over Extended Operation, Stanford, CA: AAAI Press, 2004.

[30] J. M. Bradshaw, P. J. Feltovich, H. Jung, S. Kulkarni, W. Taysom, and A. Uszok, "Dimensions of adjustable autonomy and mixed-initiative interaction," in Agents and Computational Autonomy: Potential, Risks, and Solutions, (M. Nickles, M. Rovatos, and G. Weiss, eds.), pp. 17-39, Berlin/Heidelberg: Springer, 2004.

[31] C. Breazeal, "Emotion and social humanoid robots," International Journal of Human-Computer Studies, vol. 59, pp. 119-155, 2003.

[32] C. Breazeal, "Toward sociable robots," Robotics and Autonomous Systems, vol. 42, pp. 167-175, 2003.

[33] C. Breazeal, D. Buchsbaum, J. Gray, D. Gatenby, and B. Blumberg, "Learning from and about others: Towards using imitiation to bootstrap the social understanding of others by robots," in Artificial Life Journal, (L. Rocha and F. Almedia e Costa, eds.), Cambridge, MA, USA: MIT Press, 2005.

[34] C. Breazeal, G. Hoffman, and A. Lockerd, "Teaching and working with robots as a collaboration," in Third International Joint Conference on Autonomous Agents and Multiagent Systems (AAMAS), ACM Press, 2004.

[35] C. Breazeal and B. Scassellati, "A context-dependent attention system for a social robot," in 16th International Joint Conference on Artificial Intelligence, 1999.

[36] C. Breazeal and B. Scassellati, "Infant-like social interactions between a robot and a human caregiver," Adaptive Behavior, vol. 8, no. 1, pp. 49-74, 2000.

[37] O. Brock, A. Fagy, R. Grupen, R. Platt, M. Rosenstein, and J. Sweeny, "A framework for learning and control in intelligent humanoid robots," International Journal of Humanoid Robotics, vol. 2, no. 3, 2005.

[38] R. A. Brooks, "A robust layered control system for a mobile robot," IEEE Journal of Robotics and Automation, vol. 2, pp. 14-23, 1986.

[39] R. A. Brooks, "Intelligence without representation," Artificial Intelligence, vol. 47, pp. 139-159, 1991.

[40] R. A. Brooks, Cambrian Intelligence: The Early History of the New AI. Cambridge, MA: MIT Press, 1999.

[41] A. Bruce, J. Knight, S. Listopad, B. Magerko, and I. Nourbakhsh, "Robot improv: Using drama to create believable agents," in ICRA, 2000.

[42] D. Bruemmer, J. Marble, D. Dudenhoeffer, M. Anderson, and M. McKay, "Intelligent robots for use in hazardous DOE environments," in Performance Metrics for Intelligent Systems (PERMIS), Gaithersburg, MD, USA, 2002. 
[43] D. J. Bruemmer, J. Marble, D. D. Dudenhoeffer, M. Anderson, and M. McKay, "Mixed-initiative control for remote characterization of hazardous environments," in 36th Annual Hawaii International Conference on System Sciences, Hawaii, 2003.

[44] D. J. Bruemmer and M. Walton, "Collaborative tools for mixed teams of humans and robots," in Multi-Robot Systems, Washington DC, 2003.

[45] J. L. Burke and R. R. Murphy, "Human-robot interaction in USAR technical search: Two heads are better than one," in 13th IEEE International Workshop on Robot and Human Interactive Communication (ROMAN), Kurashiki, Okayama, Japan, 2004.

[46] J. L. Burke, R. R. Murphy, E. Rogers, V. J. Lumelsky, and J. Scholtz, "Final report for the DARPA/NSF interdisciplinary study on human-robot interaction," IEEE Transactions on Systems, Man, and Cybernetics: Part $C$ Applications and Reviews, vol. 34, no. 2, pp. 103-112, 2004.

[47] R. Burridge, J. Graham, K. Shillcut, R. Hirsh, and D. Kortencamp, "Experiments with an EVA assistant robot," in 7th International Sympoisum on Artificial Intelligence, Robotics and Automation in Space, 2003.

[48] G. L. Calhoun, M. H. Draper, M. F. Abernathy, M. Patzek, and F. Delgado, "Synthetic vision system for improving unmanned aerial vehicle operator situation awareness," in Proceedings of SPIE Vol 5802, in Enhanced and Synthetic Vision 2005, (J. G. Verly, ed.), 2003.

[49] D. Casbeer, D. Kingston, R. Beard, T. McLain, W. Li, and R. Mehra, "Forest fire surveillance using a team of small unmanned air vehicles," International Journal of Systems Science, (Special issue on Cooperative Control Approaches for Multiple Mobile Robots), 2006.

[50] S. M. Casey, Set Phasers on Stun. Aegean, 1998.

[51] J. Casper and R. R. Murphy, "Human-robot interactions during the robotassisted urban search and rescue response at the World Trade Center," IEEE Transactions on Systems, Man, and Cybernetics, Part B, vol. 33, no. 3, pp. 367-385, 2003.

[52] N. Chambers, J. Allen, L. Galescu, and H. Jung, "A dialogue-based approach to multi-robot team control," in 3rd International Multi-Robot Systems Workshop, Washington DC, USA, 2005.

[53] A. Chan, K. MacLean, and J. McGrenere, "Learning and identifying haptic icons under workload," in First Joint Eurohaptics Conference and Symposium on Haptic Interfaces for Virtual Environment and Teleoperator Systems, 2005.

[54] A. Chen, A. Saenz-Otero, M. Hilstad, and D. Miller, "Development of formation flight and docking algorithms using the SPHERES testbed," in 15th Annual USU Conference on Small Satellites, 2001.

[55] J. R. Chen, "Constructing task-level assembly strategies in robot programming by demonstration," International Journal of Robotics Research, vol. 24, no. 12, pp. 1073-1085, 2005.

[56] G. Cheng, A. Nagakubo, and Y. Kuniyoshi, "Continuous humanoid interaction: An integrated perspective - gaining adaptiviry, redundancy, flexibility in one," Robotics and Autonomous Systems, vol. 37, no. (2-3), pp. 161-183, 2001. 
[57] W. J. Clancey, "Human exploration ethnography of the Haughton-Mars project 1998-1999," in Mars Society Annual Meeting, 1999.

[58] W. J. Clancey, "Field science ethnography: Methods for systematic observation on an Arctic expedition," Field Methods, vol. 13, no. 3, pp. 223-243, 2001.

[59] COGNIRON, Available from: http://www.cogniron.org/, 2004.

[60] P. R. Cohen and H. J. Levesque, "Teamwork," Nous, vol. 25, no. 4, pp. 487$512,1991$.

[61] J. L. Cooper and M. A. Goodrich, "Integrating critical interface elements for intuitive single-display aviation control of UAVs," in Proceedings of SPIE Volume 6226 Enhanced and Synthetic Vision 2006, (J. G. Verly and J. J. Guell, eds.), 2006.

[62] M. Cooper, D. Keating, W. Harwin, and K. Dautenhans, "Robots in the classroom - tools for accessible education," in Fifth European Conference of the Advancement of Assistive Technology, 1999.

[63] W. H. Corwin, "Controlled flight into terrain avoidance - why the ground proximity warning system is too little, too late," in 21st Conference of the European Association for Aviation Psychology, Dublin, Ireland, 1994.

[64] N. R. Council, in Interfaces for Ground and Air Military Robots: Workshop Summary, (T. Oron-Gilad, ed.), The National Academies Press, 2005.

[65] D. Coveney, Kismet with researcher Cynthia Breazeal, 2007.

[66] J. W. Crandall and M. A. Goodrich, "Characterizing efficiency of human robot interaction: A case study of shared-control teleoperation," in IEEE/RSJ International Conference on Intelligent Robots and Systems, Lausanne, Switzerland, 2002.

[67] J. W. Crandall and M. A. Goodrich, "Principles of adjustable interactions," in 2002 AAAI Fall Symposium Human-Robot Interaction Workshop, North Falmouth, MA, 2002.

[68] J. W. Crandall, M. A. Goodrich, D. R. Olsen Jr., and C. W. Nielsen, "Validating human-robot interaction schemes in multi-tasking environments," IEEE Transactions on Systems, Man, and Cybernetics: Part A - Systems and Humans, vol. 35, no. 4, pp. 438-449, 2005.

[69] J. W. Crandall, C. W. Nielsen, and M. A. Goodrich, "Towards predicting robot team performance," in Proceedings of the IEEE International Conference on Systems, Man, and Cybernetics, 2003.

[70] M. Cummings and S. Guerlain, "Human performance issues in supervisory control of autonomous airborne vehicles," in AUVSI Unmanned Systems North America Conference, 2004.

[71] K. Dautenhahn, "Design spaces and niche spaces of believable social robots," in IEEE International Workshop on Robot and Human Interactive Communication ROMAN, Berlin, Germany, 2002.

[72] K. Dautenhahn, "Socially intelligent robots: Dimensions of human-robot interaction," Philosophical Transactions of the Royal Society B: Biological Sciences, vol. 362, no. 1480, pp. 679-704, 2007.

[73] K. Dautenhahn, M. Walters, S. Woods, K. L. Koay, C. L. Nahaniv, E. A. Sisbot, R. Alami, and T. Siméon, "How may I serve you? A robot companion 
approaching a seated person in a helping context," in ACM Conference on Human-Robot Interaction (HRI), Salt Lake City, UT, USA: ACM Press, 2006.

[74] K. Dautenhahn, S. Woods, C. Kaouri, M. Walters, K. L. Koay, and I. Werry, "What is a robot companion - friend, assistant, or butler?," in IEEE/Robotics Society of Japan International Conference on Intelligent Robots and Systems, 2005.

[75] B. de Ruyter, P. Saini, P. Markopoulos, and A. van Breemen, "Assessing the effects of building social intelligence in a robotic interface for the home," Interacting with Computers, vol. 17, no. 5, pp. 522-541, 2005.

[76] Y. Demiris and A. Billard, eds., IEEE transactions on systems, man and cybernetics, Part B. Special Issue on Robot Learning by Observation, Demonstration, and Imitation. 2007.

[77] R. Dillman, M. Ehrenmann, P. Steinhaus, O. Rogalla, and R. Zoellner, "Human friendly programming of humanoid robots - The German collaborative research center," in Third IARP International Workshop on Humanoid and Human-Friendly Robots, 2002.

[78] S. R. Dixon, C. D. Wickens, and D. Chang, "Unmanned aerial vehicle flight control: False alarms versus misses," in Human Factors and Ergonomic Society 48th Annual Meeting, New Orleans, LA, 2004.

[79] D. Dolgin, G. Kay, B. Wasel, M. Langelier, and C. Hoffman, "Identification of the cognitive, psychomotor, and psychological skill demands of uninhabited combat aerial vehicle (UCAV) operators," SAFE Journal, vol. 30, no. 3, pp. 219-225, 2002.

[80] G. A. Dorais, R. P. Bonasso, D. Kortencamp, B. Pell, and D. Schreckenghost, "Adjustable autonomy for human-centered autonomous systems on Mars," in First International Conference of the Mars Society, 1998.

[81] G. A. Dorais and Y. Gawdiak, "The personal satellite assistant: An internal spacecraft mobile monitor," in IEEE Aerospace Conference, 2003.

[82] J. L. Drury, L. Riek, and N. Rackliffe, "A decomposition of UAV-related situation awareness," in First ACM International Conference on Human Robot Interaction, Salt Lake City, UT, USA: ACM, 2006.

[83] B. R. Duffy, "Anthropomorphism and the social robot," Robotics and Autonomous Systems, vol. 42, no. (3-4), pp. 177-190, 2003.

[84] M. Duke, S. Hoffman, and K. Snook, Lunar Surface Reference Missions: A Description of Human and Robotic Surface Activities. Houston, TX, USA: NASA Lyndon B. Johnson Space Center, 2003.

[85] K. A. Ebert and B. V. Stratton, "Supporting the joing warfighter by development, training, and fielding of man-portable UGVs," in Proceedings of SPIE, Volume 5804, (G. R. Gerhart, C. M. Shoemaker, and D. W. Gage, eds.), pp. 109-118, 2005.

[86] M. B. Edwards, D. K. Fuller, O. U. Vorrac, and C. A. Manning, The Role of Flight Progress Strips in En Route Air Traffic Control: A Time-Series Analysis. Washington, DC, 1995.

[87] ELROB, European Land-Robot Trial. 2006. Available from: http://www. elrob.org/. 
[88] M. R. Endsley, B. Bolté, and D. G. Jones, Designing for Situation Awareness: An Approach to User-Centered Design. New York: Taylor and Francis, 2003.

[89] J. A. Fails and D. R. Olsen Jr., "Interactive machine learning," in Proceedings of the 8th International Conference on Intelligent User Interfaces, Miami, FL, USA: ACM Press, 2003.

[90] D. Feil-Seifer and M. J. Mataric, "Defining socially assistive robotics," in International Conference on Rehabilitation Robotics, 2005.

[91] J. Ferketic, L. Goldblatt, E. Hodgson, S. Murray, R. Wichowski, A. Bradley, T. W. Fong, J. Evans, W. Chun, R. Stiles, M. Goodrich, and A. M. Steinfeld, "Human-robot interaction across the space enterprise," in Space 2006, San Jose, CA, USA: AIAA, 2006.

[92] J. Ferketic, L. Goldblatt, E. Hodgson, S. Murray, R. Wichowski, A. Bradley, T. W. Fong, J. Evans, W. Chun, R. Stiles, M. Goodrich, and A. M. Steinfeld, "Toward human-robot interface standards: Use of standardization and intelligent subsystems for advancing human-robotic competency in space exploration," in SAE 36th International Conference on Environmental Systems, 2006.

[93] T. Fong, "Collaborative control: A robot-centric model for vehicle teleoperation," in The Robotics Institute, Carnegie Mellon University, 2001.

[94] T. Fong, I. Nourbakhsh, and K. Dautenhahn, "A survey of socially interactive robots," Robotics and Autonomous Systems, vol. 42, pp. 143-166, 2003.

[95] T. Fong and C. Thorpe, "Vehicle teleoperation interfaces," Autonomous Robots, vol. 11, no. 1, pp. 9-18, 2001.

[96] T. Fong, C. Thorpe, and C. Baur, "A robot-centric model for vehicle teleoperation," in AAAI 1999 Spring Symposium: Agents with Adjsutable Autonomy, Stanford, CA, USA: AAAI, 1999.

[97] T. Fong, C. Thorpe, and C. Baur, "A safeguarded teleoperation controller," in IEEE International Conference on Advanced Robotics (ICAR), 2001.

[98] T. Fong, C. Thorpe, and C. Baur, Collaboration, Dialogue, and Human-Robot Interaction. Springer Tracts in Advanced Robotics. Berlin: Springer, 2003.

[99] J. Forlizzi and C. DiSalvo, "Service robots in the domestic environment: A study of the Roomba vacuum in the home," in First ACM International Conference on Human Robot Interaction, Salt Lake City, UT, USA: ACM Press, 2006.

[100] D. W. Franklin, T. W. Milner, and M. Kawato, "Single trial learning of external dynamics: What can the brain teach us about learning mechanisms?," in Brain-Inspired IT III. Invited and Selected Papers of the 3rd International Conference on Brain-Inspired Information Technology, pp. 67-70, 2007.

[101] R. Garcia, J. Battle, X. Cufi, and J. Amat, "Positioning an underwater vehicle through image mosaicking," in IEEE International Conference on Robotics and Automation, 2001.

[102] Georgia Institute of Technology, Haptic Robot. 2007. Available from: http:// www.gtresearchnews.gatech.edu/newsrelease/haptics.htm.

[103] A. R. Girard, A. S. Howell, and J. K. Hedrick, "Border patrol and surveillance missions using multiple unmanned air vehicles," in 43rd IEEE Conference on Decision and Control, 2004. 
[104] R. Gockley, A. Bruce, J. Forlizzi, M. Michalowski, A. Mundell, S. Rosenthal, B. Sellner, R. Simmons, K. Snipes, A. C. Schultz, and J. Wang, "Designing robots for long-term social interaction," in IEEE/Robotics Society of Japan International Conference on Intelligent Robots and Systems, 2005.

[105] R. Gockley, J. Forlizzi, and R. Simmons, "Natural person-following behavior for social robots," in ACM/IEEE International Conference on Human-Robot Interaction, 2007.

[106] R. Gockley, R. Simmons, and J. Forlizzi, "Modeling affect in socially interactive robots," in 15th International Symposium on Robot and Human Interactive Communication (RO-MAN), Hertforshire, Hatfield, United Kingdom, 2006.

[107] T. Goetzendorf-Grabowski, A. Frydrychewicz, Z. Goraj, and S. Suchodolski, "MALE UAV design of an increased reliability level," Aircraft Engineering and Aerospace Technology, vol. 78, no. 3, pp. 226-235, 2006.

[108] M. A. Goodrich and E. R. Boer, "Designing human-centered automation: Tradeoffs in collision avoidance system design," IEEE Transactions on Intelligent Transporation Systems, vol. 1, no. 1, 2000.

[109] M. A. Goodrich and E. R. Boer, "Model-based human-centered task automation: A case study in ACC design," IEEE Transactions on Systems, Man, and Cybernetics - Part A: Systems and Humans, vol. 33, no. 3, pp. 325-336, 2003.

[110] M. A. Goodrich, E. R. Boer, J. W. Crandall, R. W. Ricks, and M. L. Quigley, "Behavioral entropy in human-robot interaction," in PERMIS, Gaithersburg, MD, USA, 2004.

[111] M. A. Goodrich, D. R. Olsen Jr., J. W. Crandall, and T. Palmer, "Experiments in adjustable autonomy," in IJCAI-01 Workshop on Autonomy, Delegation, and Control: Interacting with Autonomous Agents, 2001.

[112] M. A. Goodrich, M. Quigley, and K. Cosenzo, "Task switching and multirobot teams," in Proceedings of the Third International Multi-Robot Systems Workshop, Washington, DC, 2005.

[113] Z. Goraj, "PW-125 MALE UAV design project developed in warsaw university of technology," in AIAA 3rd Unmanned Unlimited Technical Conference, Chicago, IL, USA: AIAA, 2004.

[114] D. Graziosi, J. Ferl, K. Splawn, D. Akin, E. Tie, J. Kosmo, and A. Ross, "Human and robotic enabling performance system development and testing," SAE Transactions, 2005.

[115] A. Green and K. S. Eklundh, "Designing for learnability in human-robot communication," in IEEE Transactions on Industrial Electronics, 2003.

[116] A. Green, H. Huttenrauch, and K. S. Eklundh, "Applying the wizard-of-Oz framework to cooperative service discovery and configuration," in IEEE International Workshop on Robot and Human Interactive Communication, 2004.

[117] A. Green, K. Severinson-Eklundh, and H. Huttenrauch, "Social and collaborative aspects of interaction with a service robot," Robotics and Autonomous Systems, vol. 42, no. 3-4, pp. 223-234, 2003.

[118] P. Grice, Studies in the Way of Words. Cambridge, MA, USA: Harvard University Press, 1989. 
[119] J. P. Gunderson and L. F. Gunderson, "Intelligence $\neq$ Autonomy $\neq$ Capability," in Performance Metrics for Intelligent Systems, PERMIS, Gaithersburg, MD, USA, 2004.

[120] W. C. Gunhee Kim, K.-R. Kim, M. Kim, S. Han, and R. H. Shinn, "The autonomous tour-guide robot Jinny," in IEEE/Robotics Society of Japan International Conference on Intelligent Robots and Systems, 2004.

[121] P. A. Hancock, M. Mouloua, R. Gilson, J. Szalma, and T. Oron-Gilad, "Is the UAV control ratio the right question?" Ergonomics in Design, 2006.

[122] M. A. Hearst, "Mixed-initiative interaction: Trends and controversies," IEEE Intelligent Systems, pp. 14-23, 1999.

[123] J. M. Histon and R. J. Hansman, The Impact of Structure on Cognitive Complexity in Air Traffic Control. Cambridge, MA, USA: MIT International Center for Air Transport, 2002.

[124] T. Hoeniger, "Dynamically shared control in human-robot teams through physical interactions," in IEEE/Robotics Society of Japan International Conference on Intelligent Robots and Systems, 1998.

[125] Homer The Iliad. Vol. Book XVIII. circa 800 BC.

[126] J. H. Hong, Y. S. Song, and S. B. Cho, "A hierarchical bayesian network for mixed-initiative human-robot interaction," in IEEE International Conference on Robotics and Automation, 2005.

[127] T. N. Hornyak, Loving the Machine: The Art and Science of Japanese Robots. Kondansha International, 2006.

[128] I. D. Horswill, "Functional programming of behavior-based systems," Autonomous Robots, vol. 9, no. 1, pp. 83-93, 2000.

[129] T. Huntsberger, G. Rodriguez, and P. Schenker, "Robotics challenges for robotic and human mars exploration," in Robotics, 2000.

[130] E. Hutchins, Cognition in the Wild. Cambridge, MA, USA: MIT Press, 1995.

[131] H. Huttenrauch and K. S. Eklundh, "Fetch-and-carry with CERO: Observations from a long-term user study with a service robot," in IEEE International Workshop on Robot and Human Interactive Communication (ROMAN), 2002.

[132] T. Inagaki, "Situation-adaptive responsibility allocation for human-centered automation," Transactions of the Society of Instrument and Control Engineers, vol. 31, no. 3, pp. 292-298, 1995.

[133] T. Inagaki and K. Inoue, "Adaptive choice of a safety management scheme upon an alarm under supervisory control of a large-complex system," Reliability Engineering and System Safety, vol. 39, pp. 81-87, 1993.

[134] S. H. Inhyuk Moon and Y. Kum, "Safe and reliable intelligent wheelchair robot with human robot interaction," in IEEE International Conference on Robotics and Automation, 2002.

[135] iRobot Packbot §. Available from: http://www.irobot.com/creative\%5Fassets/default.asp?dir_ID=19, 2007.

[136] H. Ishiguro, The robot Repliee from Osaka University. http:// www.ed.ams. eng.osaka-u.ac.jp/, 2007.

[137] P. Jacobs, "When is a garden ... not a garden? The garden festival at Grand Métis, Québec, invites designers to go to the limit - and then some," Landscape Architecture, vol. 10, 2003. 
[138] A. Jacoff, E. Messina, and J. Evans, "A standard test course for urban search and rescue robots," in Performance Metrics for Intelligent Systems, Gaithersburg, MD, USA, 2000.

[139] M. Jamshidi and P. Eicker, Robotics and Remote Systems for Hazardous Environments. Englewood Cliffs, NJ: Prentice Hall, 1993.

[140] M. J. Jeonghye Han, S. Park, and S. Kim, "The educational use of home robots for children," in IEEE International Workshop on Robots and Human Interactive Communication (ROMAN), 2005.

[141] J. P. Jinsul Kim, Y. K. Hwant, and M. Lee, "Advanced grasp planning for handover operation between human and robot: Three handover methods in esteem etiquettes using dual arms and hands of home-service robot," in International Conference on Autonomous Robots and Agents, 2004.

[142] P. N. Johnson-Laird, The Computer and the Mind: An Introduction to Cognitive Science. Harvard University Press, 1988.

[143] J. Johnston, S. M. Fiore, C. Paris, and C. A. P. Smith, "Application of cognitive load theory to developing a measure of team decision efficiency," Military Psychology, 2006.

[144] D. B. Kaber and M. R. Endsley, "The Effects of Level of Automation and Adaptive Automation on Human Performance, Situation Awareness and Workload in a Dynamic Control Task," Theoretical Issues in Ergonomics Science, vol. 5, no. 2, pp. 113-153, 2004.

[145] M. W. Kadous, R. K.-M. Sheh, and C. Sammut, "Effective user interface design for rescue robotics," in ACM Conference on Human-Robot Interaction, Salt Lake City, UT, USA: ACM Press, 2006.

[146] M. Kaiser and R. Dillman, "Building elementary robot skills from human demonstration," in IEEE International Conference on Robotics and Automation, 1996.

[147] G. A. Kaminka and Y. Elmaliach, "Experiments with an ecological interface for monitoring tightly-coordinated robot teams," in Proceedings of the 2006 IEEE International Conference on Robotics and Automation, Orlando, FL, 2006.

[148] T. Kanda, T. Hirano, D. Eaton, and H. Ishiguro, "Interactive robots as social partners and peer tutors for children: A field trial," Human-Computer Interaction, vol. 19, no. 1-2, pp. 61-84, 2004.

[149] T. Kanda, R. Sato, N. Saiwaki, and H. Ishiguro, "Friendly social robot that understands human's friendly relationships," IEEE/Robotics Society of Japan International Conference on Intelligent Robots and Systems, 2004.

[150] F. Kaplan, "Who is afraid of the humanoid? Investigating cultural differences in the acceptance of robots," International Journal of Humanoid Robotics, vol. 1, no. 3, pp. 1-16, 2004.

[151] H. Kautz, L. Arnstein, G. Borriello, O. Etzioni, and D. Fox, "An overview of the assisted cognition project," in AAAI Workshop on Automation as Caregiver: The Role of Intelligent Technology in Elder Care, 2002.

[152] K. Kawamura and M. Iskarous, "Trends in service robots for the disabled and the elderly," in IEEE/Robotics Society of Japan/GI International Conference on Advanced Robots Systems and the Real World (IROS), 1994. 
[153] K. Kawamura, P. Nilas, K. Muguruma, J. A. Adams, and C. Zhou, "An agentbased architecture for an adaptive human-robot interface," in 36th Annual Hawaii International Conference on System Sciences, Hawaii, 2003.

[154] H. Kaymaz Keskinpala, J. A. Adams, and K. Kawamura, "PDA-based humanrobotic interface," in IEEE International Conference on Systems, Man, and Cybernetics, Washington, DC, 2003.

[155] W. G. Kennedy, M. Bugajska, M. Marge, W. Adams, B. R. Fransen, D. Perzanowski, A. C. Schultz, and J. G. Trafton, "Spatial representation and reasoning for human-robot collaboration," in AAAI National Conference on Artificial Intelligence, 2007.

[156] S. Kiesler and J. Goetz, "Mental models of robotic assistants," in CHI 2002, ACM Press: Minneapolis, MN, USA, 2002.

[157] S. Kiesler and P. J. Hinds, eds., Human-computer interaction. Special Issue on Human-Robot Interaction. Vol. 19, no. 1\&2, 2004.

[158] H. J. Kim, H. Lee, and C. Kim, "Autonomous behavior design for robotic appliance," in ACM/IEEE International Conference on Human-Robot Interaction, 2007.

[159] H. Kitano, S. Tadokoro, I. Noda, H. Matsubara, T. Takahsahi, A. Shinjou, and S. Shimada, "RoboCup rescue: Search and rescue in large-scale disasters as a domain for autonomous agents research," in IEEE International Conference on Systems, Man, and Cybernetics, 1999.

[160] G. Klein, P. J. Feltovich, J. M. Bradshaw, and D. D. Woods, "Common ground and coordination in joint activity," in Organizational Simulation, (W. B. Rouse and K. R. Boff, eds.), pp. 139-184, John Wiley and Sons, 2005.

[161] K. Konolige, "Large-scale map making," in National Conference on AI (AAAI), San Jose, CA, 2004.

[162] D. Kortencamp, P. Bonasso, D. Ryan, and D. Schreckenghost, "Traded control with autonomous robots as mixed initiative interaction," in AAAI Symposium on Mixed Initiative Interaction, Stanford, CA, USA, 1997.

[163] K. Kosuge, T. Hayashi, Y. Hirata, and R. Tobiyama, "Dance partner robots Ms. DancerR," in IEEE/RSH International Conference on Intelligent Robots and Systems, Las Vegas, NV, USA, 2003.

[164] A. Kron, G. Schmidt, B. Petzold, M. I. Zah, P. Hinterseer, and E. Steinbach, "Disposal of explosive ordnances by use of a bimanual haptic telepresence system," in IEEE International Conference on Robotics and Automation, 2004.

[165] E. Krotkov, R. Simmons, F. Cozman, and S. Koenig, "Safeguarded teleoperation for lunar rovers: From human factors to field trials," in IEEE Planetary Rover Technology and Systems Workshop, 1996.

[166] S. K. Kuk-Hyun Han, Y.-J. Kim, and J.-H. Kim, "Internet control architecture for internet-based personal robot," Autonomous Robots, vol. 10, no. 2, pp. 135$147,2001$.

[167] V. Kulyukin, C. Gharpure, J. Nicholson, and G. Osborne, "Robot-assisted wayfinding for the visually impaired in structured indoor environments," Autonomous Robots, vol. 21, no. 1, pp. 29-41, 2006.

[168] V. Kulyukin and G. Gharpure, "A robotic shopping assistant for the blind," in Rehabilitation Engineering and Assistive Technology Society of North America Conference, Atlanta, GA, USA, 2006. 
[169] LAAS-CNRS EU-FP6-IST-FET-002020 Cogniron project, Available from: http://www.cogniron.org/RA6.php.

[170] G. Lacey and K. M. Dawson-Howe, "The application of robotics to a mobility aid for the elderly blind," Robotics and Autonomous Systems, vol. 23, no. 4, pp. 245-252, 1998.

[171] C. Laschi, C. Breazeal, and Y. Nakauchi, eds., IEEE transactions on robotics. Special issue on Human-Robot Interaction. 2007.

[172] K. Lay, E. Prassler, R. Dillmann, G. Grunwald, M. Hagele, G. Lawitzky, A. Stopp, and W. von Seelen, "MORPHA: Communication and interaction with intelligent, anthropomorphic robot assistants," in Tagungsband Statustage Leitprojekte Mensch-Technik-Interaktion in der Wissensgesellschaft, Saarbrucken, Germany, 2001.

[173] J. D. Lee and K. A. See, "Trust in Automation," Human Factors, 2003.

[174] P. C. Leger, A. Trebi-Ollennu, J. R. Wright, S. A. Maxwell, R. G. Bonitz, J. J. Biesiadecki, F. R. Hartman, B. K. Cooper, E. T. Baumgartner, and M. W. Maimone, "Mars exploration rover surface operations: Driving spirit at gusev crater," in IEEE International Conference on Systems, Man, and Cybernetics, Hawaii, 2005.

[175] F. L. Lewis, Optimal Control. New York: John Wiley and Sons, 1986.

[176] J. Long, The Madeleine Underwater Robot. Available from: http://www. nsf.gov/news/newsletter/jun_06/index.jsp, 2007.

[177] W. Long, "Chinese robots to land on moon before yuhangyuan," in Space Daily: Your Portal to Space, 2000.

[178] P. S. Lum, C. G. Burgar, P. C. Shor, M. Majmundar, and M. Van der Loos, "Robot-assisted movement training compared with conventional therapy techniques for the rehabilitation of upper-limb motor function after stroke," Archives of Physical Medicine and Rehabilitation, vol. 83, pp. 952959, 2002.

[179] K. F. MacDorman, "Subjective ratings of robot video clips for human likeness, familiarity, and eeriness: An exploration of the uncanny valley," in ICCS/CogSci, 2006 Long Symposium: Toward Social Mechanisms of Android Science, 2006.

[180] P. Marayong, A. Bettini, and A. Okamura, "Effect of virtual fixture compliance on human-machine cooperative manipulation," in IEEE/Robotics Society of Japan International Conference on Intelligent Robots and Systems, 2002.

[181] M. Mataric', S. Schaal, G. Sukhatme, and M. Nicolescu, NSF PI Workshop on Human-Robot Interaction. USC Davidson Executive Conference Center, 2006.

[182] J. S. McCarley and C. D. Wickens, Human Factors Implications of UAVs in the National Airspace. Savoy, IL: University of Illinois, 2005.

[183] A. Meystel, "Intelligent systems: A semiotic perspective," in IEEE International Symposium on Intelligent Control, Dearborn, MI, 1996.

[184] A. Meystel, "Multiresolutional Autonomy," in Intelligent Control (ISIC), IEEE: Gaithersburg, MD, USA, 1998.

[185] P. Milgram, A. Rastogi, and J. J. Grodski, "Telerobotic control using augmented reality," in 4th International Workshop on Robot and Human Communication (RO-MAN95), Tokyo, 1995. 
[186] Military.com, Raven. 2007.

[187] C. A. Miller, H. B. Funk, M. Dorneich, and S. D. Whitlow, "A playbook interface for mixed initiative control of multiple unmanned vehicles," in 21st Digital Avionics Systems Conference, Irvine, CA, USA, 2002.

[188] C. A. Miller and R. Parasuraman, "Beyond levels of automation: An architecture for more flexible human automation and collaboration," in Human Factors and Ergonomics Society 47th Annual Meeting, 2003.

[189] MIT, Leonardo. 2007.

[190] P. M. Mitchell and M. L. Cumings, "Management of multiple dynamic human supervisory control tasks," in 10th International Command and Control Research and Technology Symposium, MacLean, VA, USA, 2005.

[191] J. Montemayor, H. Alborizi, A. Druin, J. Hendler, D. Pollack, J. Porteous, L. Sherman, A. Afework, J. Best, J. Hammer, A. Kruskal, and A. Lal, "From PETS to storykit: Creating new technology with and intergenerational design team," in Workshop on Interactive Robots and Entertainment (WIRE), Pittsburgh, PA, USA, 2000.

[192] M. Montemerlo, J. Pineau, N. Roy, S. Thrun, and V. Verma, "Experiences with a mobile robotic guide for the elderly," in AAAI National Conference on Artificial Intelligence, 2002.

[193] N. Moray, "Designing for transportation safety in the light of perception, attention, and mental models," Ergonomics, vol. 33, no. (10/11), pp. 1201$1213,1990$.

[194] M. Mori, "Uncanny valley," Energy, vol. 7, no. 4, 1970.

[195] M. Mulder, "An information-centered analysis of the tunnel-in-the-sky display, part one: Straight tunnel trajectories," International Journal of Aviation Psychology, vol. 13, no. 1, pp. 49-72, 2003.

[196] R. R. Murphy, Introduction to AI Robotics. Cambridge, MA, USA: The MIT Press, 2000.

[197] R. R. Murphy, "Human-robot interaction in rescue robotics," IEEE Transactions on Systems, Man, and Cybernetics: Part $C-$ Applications and Reviews, vol. 34, no. 2, 2004.

[198] R. R. Murphy, "National Science Foundation summer field institute for rescue robots for research and response (R4)," AI Magazine, vol. 25, no. 2, pp. 133136, 2004.

[199] R. R. Murphy, J. Casper, M. Jicire, and J. Hyams, "Assessment of the NIST standard test bed for urban search and rescue," in NIST Workshop on Performance Metrics for Intelligent Systems, Gaithersburg, MD, USA, 2000.

[200] R. R. Murphy and J. J. Martinez, Lessons Learned from the NSF REU Site Grant: Multiple Autonomous Mobile Robots for Search and Rescue Applications. Frontiers in Education, 1997.

[201] R. R. Murphy and E. Rogers, eds., IEEE transactions on systems, man, and cybernetics: Part $C-$ Applications and reviews. Special Issue on HumanRobot Interaction. Vol. 34, no. 2, 2004.

[202] J. Nakanishi, J. Morimoto, G. Endo, G. Cheng, S. Schaal, and M. Kawato, "Learning from demonstration and adaptation of biped locomotion," Robotics and Autonomous Systems, vol. 47, no. 2-3, pp. 79-91, 2004. 
[203] Y. Nakauchi and R. Simmons, "A social robot that stands in line," Autonomous Robots, vol. 12, no. 3, pp. 313-324, 2004.

[204] NASA, Task Load Index (NASA-TLX). 1987.

[205] NASA Robonaut, Available from: http://robonaut.jsc.nasa.gov/gallery.htm, 2007.

[206] Y. Nemoto, S. Egawa, A. Koseki, S. Hattori, T. Ishii, and M. Fujie, "Powerassisted walking support system for elderly," in IEEE International Conference on Engineering in Medicine and Biology, 1998.

[207] M. N. Nicolescu and M. J. Mataric, "Learning and interacting in humanrobot domains," IEEE Transactions on Systems, Man, and Cybernetics, Part $A$, vol. 31, no. 5, pp. 419-430, 2001.

[208] C. W. Nielsen and M. A. Goodrich, "Comparing the usefulness of video and map information in navigation tasks," in First ACM International Conference on Human-Robot Interaction, Salt Lake City, UT, USA: ACM Press, 2006.

[209] N. Nilsson, Shakey the Robot. SRI AI Center Technical Note, 1984.

[210] I. R. Norbakhsh, C. Kunz, and T. Willeke, "The mobot museum robot installations: A five year experiment," in 2003 IEEE/RSJ International Conference on Intelligent Robots and Systems, Las Vegas, NV, USA, 2003.

[211] I. R. Norbakhsh, K. Sycara, M. Koes, M. Yong, M. Lewis, and S. Burion, "Human-robot teaming for search and rescue," in Pervasive Computing, pp. 72-79, IEEE, 2005.

[212] D. A. Norman, "The design of everyday things," Currency Doubleday, 1988.

[213] I. R. Nourbakhsh, K. Sycara, M. Koes, M. Yong, M. Lewis, and S. Burion, "Human-robot teaming for search and rescue," IEEE Pervasive Computing, vol. 4, no. 1, pp. 72-29, 2005.

[214] A. Nunes and R. H. Mogford, "Identifying controller strategies that support the 'picture'," in 47th Annual Meeting of the Human Factors and Ergonomics Society, HFES: Santa Monica, CA, USA, 2003.

[215] B. Ogden and K. Dautenhahn, "Robotic etiquette: Structured interations in humans and robots," in Symposium on Intelligent Robotic Systems, 2000.

[216] D. R. Olsen Jr. and M. A. Goodrich, "Metrics for evaluating human-robot interactions," in PERMIS, Gaithersburg, MD, USA, 2003.

[217] D. R. Olsen Jr. and S. B. Wood, "Fan-out: Measuring human control of multiple robots," in Human Factors in Computing Systems, pp. 231-238, Vienna, Austria: ACM Press, 2004.

[218] H. Onda, K. Kitagaki, and T. Suehiro, "Visualization and simulation of sensory events as a representation of states for state-based teaching by demonstration in VR," in IEEE/Robotics Society of Japan International Conference on Intelligent Robots and Systems, 2005.

[219] M. Onishi, "In a wired South Korea, robots will feel right at home," in The New York Times, 2006.

[220] E. Pacchierotti, H. I. Christensen, and P. Jensfelt, "Evaluation of passing distance for social robots," in IEEE International Workshop on Robot and Human Interactive Communication, 2006. 
[221] R. Parasuraman, S. Galster, and C. Miller, "Human control of multiple robots in the roboflag simulation environment," in 2003 IEEE International Conference on Systems, Man, and Cybernetics, Washington, DC, 2003.

[222] R. Parasuraman, T. B. Sheridan, and C. D. Wickens, "A model for types and levels of human interaction with automation," IEEE Transactions on Systems, Man, and Cybernetics, Part A, vol. 30, no. 3, pp. 286-297, 2000.

[223] L. E. Parker, "ALLIANCE: An architecture for fault tolerant, cooperative control of heterogeneous mobile robots," in Proceedings of IEEE/RSJ/GI International Conference on Intelligent Robots and Systems, pp. 776-783, Munich, Germany, 1994.

[224] S. Payandeh and Z. Stanisic, "On application of virtual fixtures as an aid for telemanipulation and training," in Symposium on Haptic Interfaces for Virtual Environment and Teleoperator Systems, 2002.

[225] L. Pederson, D. Kortencamp, D. Wettergreen, and I. Nourbakhsh, "A survey of space robotics," in 7th International Symposium on Artificial Intelligence, Robotics, and Automation in Space, Munich, Germany, 2003.

[226] D. Perzanowski, A. Schultz, W. Adams, E. Marsh, and M. Bugajska, "Building a multimodal human-robot interface," Intelligent Systems, vol. 16, no. 1, pp. 16-21, 2001.

[227] D. Perzanowski, A. C. Schultz, W. Adams, and E. Marsh, "Goal tracking in a natural language interface: Towards achieving adjustable autonomy," in IEEE International Symposium on Computational Intelligence in Robotics and Automation, pp. 208-213, Monterey, CA, 1999.

[228] M. A. Peshkin, J. E. Colgate, W. Wannasuphoprasit, C. A. Moore, R. B. Gillespie, and P. Akella, "Cobot architecture," IEEE Transactions on Robotics and Automation, vol. 17, no. 4, pp. 377-390, 2001.

[229] R. W. Picard, Affective Computing. Cambridge, MA: MIT Press, 1997.

[230] M. Plumlee and C. Ware, "An evaluation of methods for linking 3D views," in 2003 Symposium on Interactive 3D Graphics, Monterey, CA, USA: ACM, 2003.

[231] M. E. Pollack, "Intelligent technology for an aging population: The use of AI to assist elders with cognitive impairment," AI Magazine, vol. 26, no. 2, pp. 9-24, 2005.

[232] M. E. Pollack, L. Brown, D. Colbry, C. Orosz, B. Peintner, S. Ramkrishnan, S. Engberg, J. Matthews, J. Dunbar-Jacob, C. McCarthy, S. Thrun, M. Montemerlo, J. Pineau, and N. Roy, "Pearl: A mobile robotic assistant for the elderly," in AAAI Workshop on Automation as Caregiver, 2002.

[233] N. S. Pollard, J. K. Hodgins, M. J. Riley, and C. G. Atkeson, "Adapting human motion for the control of a humanoid robot," in IEEE International Conference on Robotics and Automation, 2002.

[234] Z. Pronk and M. Schoonmade, Mission Preparation and Training Facility for the European Robotic Arm (ERA). National Aerospace Laboratory, 1999.

[235] A. K. Raj, S. J. Kass, and J. F. Perry, "Vibrotactile displays for improving spatial awareness," in IEA/HFES 2000 Congress, Santa Monica, CA, USA, 2000 . 
[236] P. Rani, N. Sarkar, C. A. Smith, and J. A. Adams, "Anxiety detection for implicit human-machine interaction," in IEEE International Conference on Systems, Man, and Cybernetics, 2003.

[237] J. Rasmussen, "Outlines of a hybrid model of the process plant operator," in Monitoring Behavior and Supervisory Control, (T. B. Sheridan and G. Johannsen, eds.), pp. 371-383, Plenum, 1976.

[238] B. Reeves and C. Nass, The Media Equation: How People Treat Computers, Television, and New Media Like Real People and Places. Cambridge University Press, 1996.

[239] Rescue Robotics Camp, Available from: http://net143-184.mclink.it/ camp04/, 2004.

[240] Rescue Robotics Camp, Available from: http://sied.dis.uniroma1.it/ssr-r07/ index.php?option=com_content\&task $=$ view\&id $=23 \&$ Itemid $=37,2007$.

[241] J. Richer and J. L. Drury, "A video game-based framework for analyzing human-robot interaction: Characterizing interface design in real-time interactive media applications," in First ACM International Conference on HumanRobot Interaction, ACM press: Salt Lake City, UT, USA, 2006.

[242] J. M. Riley, D. B. Kaber, and J. V. Draper, "Situation awareness and attention allocation measures for quantifying telepresence experiences in teleoperation," Human Factors and Ergonomics in Manufacturing, vol. 14, no. 1, pp. 51-67, 2003.

[243] J. Riskin, "The defecating duck, or, the ambiguous origins of artificial life," Critical Inquiry, vol. 29, pp. 599-633, 2003.

[244] F. E. Ritter, D. Van-Rooy, and R. St. Amant, "Using a simulated user to explore human robot interfaces," in ACT-R Workshop, 2005.

[245] B. Robins, K. Dautenhahn, R. te Boerkhorst, and A. Billard, "Effects of repeated exposure to a humanoid robot on children with autism," in Designing a More Inclusive World, (S. Keates, J. Clarkson, P. Landong, and P. Robinson, eds.), pp. 225-236, London: Springer-Verlag, 2004.

[246] B. Robins, K. Dautenhahn, R. te Boerkhorst, and A. Billard, "Robots as assistive technology - does appearance matter?," in IEEE International Workshop on Robot and Human Communication (ROMAN), 2004.

[247] B. Robins, P. Dickerson, P. Stribling, and K. Dautenhahn, "Robot-mediated joint attention in children with autism: A case study in robot-human interaction," Interaction Studies, vol. 5, no. 2, pp. 161-198, 2004.

[248] O. Rogalla, M. Ehrenmann, R. Zollner, R. Becher, and R. Dillmann, "Using gesture and speech control for commanding a robot assistant," in IEEE International Workshop on Robot and Human Interactive Communication, Berlin, Germany, 2002.

[249] E. Rogers, R. R. Murphy, and B. Ericson, "Agent-based expert assistance for visual problem solving," in First International Conference on Autonomous Agents, Marina Del Rey, CA, USA: ACM Press, 1997.

[250] M. E. Rosheim, Leonardo's Lost Robot. Berlin: Springer Verlag, 2006.

[251] D. Roy, "Learning words and syntax for a visual description task," Computer Speech and Language, vol. 16, no. 3, pp. 353-385, 2002. 
[252] N. Roy, G. Baltus, D. Fox, F. Gemperle, J. Goetz, T. Hirsch, D. Magaritis, M. Montemerlo, J. Pineau, N. Roy, J. Schulte, and S. Thrun, "Towards personal service robots for the elderly," in Workshop on Interactive Robotics and Entertainment, Pittsburgh, PA, USA, 2000.

[253] S. J. Russell and P. Norvig, Artificial Intelligence: A Modern Approach. Upper Saddle River, NJ: Pearson Education Inc, 2nd ed., 2003.

[254] T. Salter, K. Dautenhahn, and R. te Boekhorst, "Learning about natural human-robot interaction styles," Robotics and Autonomous Systems, vol. 54, pp. 127-134, 2006.

[255] G. N. Saridis, "Analytic formulation of the principle of increasing precision with decreasing intelligence for intelligent machines," Automatica, vol. 25, no. 3, pp. 461-467, 1989.

[256] G. N. Saridis, Hierarchically Intelligent Machines. London: World Scientific, 2001.

[257] J. Saunder, C. L. Nehaniv, and K. Dautenhahn, "Teaching robots by moulding behavior and scaffolding the environment," in ACM SIGCHI/SIGART International Conference on Human-Robot Interaction, 2006.

[258] J. Saunders, C. Nehaniv, and K. Dautenhahn, "Using self-imitation to direct learning," in 15th IEEE International Symposium on Robot and Human Interactive Communication (RO-MAN), Hatfield, UK: University of Hertfordshire, 2006.

[259] P. Scerri, D. V. Pynadath, and M. Tambe, "Towards adjustable autonomy for the real world," Journal of Artificial Intelligence Research, vol. 17, pp. 171$228,2002$.

[260] M. Scheef, J. Pinto, K. Rahardja, S. Snibbe, and R. Tow, "Experiences with Sparky, a social robot," in Socially Intelligent Agents, (K. Dautenhahn, A. Bond, L. Canamero, and B. Edmonds, eds.), pp. 173-180, Springer, 2002.

[261] J. Scholtz, ed., ACM interactions: New visions of human-computer interaction. Special Issue on Robots. Vol. 12, no. 2, 2005.

[262] J. Scholtz, M. Theofanos, and B. Antonishek, "Theory and evaluation of human robot interactions," in 36th International Conference on Systems Sciences, Hawaii: IEEE, 2002.

[263] J. Scholtz, M. Theofanos, and B. Antonishek, "Development of a test bed for evaluating human-robot performance for explosive ordnance disposal," in First ACM International Conference on Human-Robot Interaction, pp. 10-17, Salt Lake City, UT, USA: ACM Press, 2006.

[264] J. Scholtz, J. Young, L. Drury, and H. A. Yanco, "Evaluation of human-robot interaction awareness in search and rescue," in Proceedings of the 2004 IEEE International Conference on Robotics and Automation, pp. 2327-2332, New Orleans, LA, USA, 2004.

[265] A. C. Schultz, M. A. Goodrich, and D. Bruemmer, eds., Proceedings of the First ACM International Conference on Human-Robot Interaction, Salt Lake City, UT, USA: ACM Press, 2006.

[266] B. Sellner, F. W. Heger, L. M. Hiatt, R. Simmons, and S. Singh, "Coordinated multi-agent teams and sliding autonomy for large-scale assembly," Proceedings of the IEEE, vol. 94, no. 7, 2006. 
[267] T. B. Sheridan, Telerobotics, Automation, and Human Supervisory Control. Cambridge, MA: MIT Press, 1992.

[268] T. B. Sheridan, Humans and Automation: System Design and Research Issues. John Wiley and Sons, 2002.

[269] T. B. Sheridan and W. L. Verplank, Human and Computer Control for Undersea Teleoperators. MIT Man-Machine Systems Laboratory, 1978.

[270] T. Shibata, "An overview of human interactive robots for psychological enrichment," Proceedings of the IEEE, vol. 92, no. 11, pp. 1749-1758, 2004.

[271] T. Shibata and K. Tanie, "Influence of a priori knowledge in subjective interpretation and evaluation by short-term interaction with mental commit robot," in IEEE/Robotics Soceity of Japan International Conference on Intelligent Robots and Systems, 2000.

[272] T. Shibata, T. Tashima, and K. Tanie, "Emergence of emotional behavior through physical interaction between human and robot," in IEEE International Conference on Robotics and Automation, 1999.

[273] M. Shimada, T. Minato, S. Itakur, and H. Ishiguro, "Development of androids for studying human-robot interaction," in Proceedings of the 6th IEEE-RAS International Conference on Humanoid Robots, Genoa, Italy, 2006.

[274] S. Shoval, J. Borenstein, and Y. Koren, "Mobile robot obstacle avoidance in a computerized travel aid for the blind," in IEEE Conference on Robotics and Automation, San Diego, CA, USA: IEEE, 1994.

[275] C. L. Sidner, C. D. Kidd, C. Lee, and N. Lesh, "Where to look: A study of human-robot engagement," in Intelligent User Interfaces, Madeira, Funchal, Portugal: ACM Press, 2004.

[276] R. Simmons, A. Bruce, D. Goldberg, A. Goode, M. Montemerlo, N. Roy, B. Sellner, C. Urmson, A. Schultz, W. Adams, M. Bugajska, M. MacMahon, J. Mink, D. Perzanowski, S. Rosenthal, S. Thomas, I. Horswill, R. Zubek, D. Kortencamp, B. Wolfe, T. Milam, and B. Mazwell, "GRACE and GEORGE: Autonomous robots for the AAAI robot challenge," in Workshop Paper for AAAI 2003, 2003.

[277] M. Skubic, D. Anderson, S. Blisard, D. Perzanowski, and A. Schultz, "Using a qualitative sketch to control a team of robots," in Proceedings of the 2006 IEEE International Conference on Robotics and Automation, Orlando, FL, 2006.

[278] Small Unmanned Aircraft Search for Survivors in Katrina Wreckage, in Science Daily, 2005.

[279] SRI International. Shakey the robot, 2007.

[280] A. Steinfeld, T. Fong, D. Kaber, M. Lewis, J. Scholtz, A. Schultz, and M. Goodrich, "Common metrics for human-robot interaction," in First ACM International Conference on Human Robot Interaction, Salt Lake City, UT, USA: ACM, 2006.

[281] R. Stiefelhagen, C. Fugen, R. Gieselmann, H. Holzapfel, K. Nickel, and A. Waibel, "Natural human-robot interaction using speech, head pose and gestures," in IEEE/RSJ International Conference on Intelligent Robots and Systems (IROS), Sendai, Japan, 2004. 
[282] R. J. Stone, "Haptic feedback: A brief history from telepresence to virtual reality," in First International Workshop on Haptic Human-Computer Interaction, Glasgow, UK: Springer, 2000.

[283] K. Stubbs, P. Hinds, and D. Wettergreen, "Challenges to grounding in humanrobot interaction," in First ACM International Conference on Human-Robot Interaction, Salt Lake City, Utah, USA, 2006.

[284] H. Surmann, A. Nüchter, and J. Hertzberg, "An autonomous mobile robot with a 3D laser range finder for 3D exploration and digitalization of indoor environments," Robotics and Autonomous Systems, vol. 45, pp. 191-198, 2003.

[285] S. Tachi, K. Komoriya, K. Sawada, T. Nishiyama, T. Itoki, M. Kobayashi, and K. Inoue, "Telexistance cockpit for humanoid robot control," Advanced Robotics, vol. 17, no. 3, pp. 199-217, 2003.

[286] W. Taggart, S. Turkle, and C. D. Kidd, "An interactive robot in a nursing home: Preliminary remarks," in Towards Social Mechanisms of Android Science: A COGSCI Workshop, Stresa, Italy: Cognitive Science Society, 2005.

[287] N. Tesla Tesla's boat, Available from: http://www.brotherhoodoflife. com/Tesla-boat.jpg.

[288] IEEE Transactions on Intelligent Transporation Systems 2000-2006, Piscataway, NJ: IEEE.

[289] S. Thrun, "Learning maps for indoor mobile robot navigation," Artificial Intelligence, vol. 99, pp. 21-71, 1998.

[290] S. Thrun, Stanford Racing Team's Entry in the 2005 DARPA Grand Challenge. 2005.

[291] S. Thrun, M. Beetz, M. Bennewitz, W. Burgard, A. B. Cremers, F. Dellaert, D. Fox, D. Hähnel, C. Rosenberg, N. Roy, J. Schulte, and D. Schulz, "Probabilistic algorithms and the interactive museum tour-guide robot minerva," The International Journal of Robotics Research, vol. 19, no. 11, pp. 972-999, 2000 .

[292] S. Thrun, M. Bennewitz, W. Burgard, A. B. Cremers, F. Dellaert, D. Fox, D. Hahnel, C. Rosenberg, N. Roy, J. Schulte, and D. Schulz, "MINERVA: A second-generation museum tour-guide robot," in IEEE International Conference on Robotics and Automation, 1999.

[293] S. Thrun, S. Thayer, W. Whittaker, C. Baker, W. Burgard, D. Ferguson, D. Hahnel, D. Montemerlo, A. Morris, Z. Omohundro, C. Reverte, and W. Whittaker, "Autonomous exploration and mapping of abandoned mines," in IEEE Robotics and Automation Magazine, pp. 79-91, 2004.

[294] G. Trafton, Experimental Design in HRI. 2007. Tutorial at HRI2007. Available from: http://hri2007.org/Tutorials.htm.

[295] J. G. Trafton, A. C. Schultz, D. Perznowski, M. D. Bugajska, W. Adams, N. L. Cassimatis, and D. P. Brock, "Children and robots learning to play hide and seek," in First ACM International Conference on Human-Robot Interaction, Salt Lake City, UT, USA: ACM Press, 2006.

[296] K. S. Tyree, "Robotic assistance for human planetary and lunar exploration," in Space 2004, San Diego, CA, USA: AIAA, 2004.

[297] M. Tzu, Book of Master Mo. circa 400 BC. 
[298] University of Hertfordshire. The Kaspar robot, Available from: http:// kaspar.feis.herts.ac.uk/, 2007.

[299] H. F. M. Van der Loos, J. J. Wagner, N. Smaby, K. Chang, O. Madrigal, L. J. Leifer, and O. Khatib, "ProVAR assistive robot system architecture," in IEEE International Conference on Robotics and Automation, 1999.

[300] K. Vincente, "Should an interface always match the operator's mental model?" CSERIAC Gateway, vol. 8, no. 1, 1997.

[301] K. Vincenti, Cognitive Work Analysis: Towards Safe, Productive and Healthy Computer-Based Work. Lawrence Erlbaum Associates, 1999.

[302] A. Visser, J. Sturm, and F. Groen, "Robot companion localization at home and in the office," in 18th Dutch-Belgian Artificial Intelligence Conference, Namen, Belgium, 2006.

[303] K. Wada, T. Shibata, T. Saito, and K. Tanie, "Analysis of factors that bring mental effects to elderly people in robot assisted activity," in IEEE/RSJ International Conference on Intelligent Robots and Systems, 2002.

[304] K. Wada, T. Shibata, T. Saito, and K. Tanie, "Robot assisted activity for elderly people and nurses at a day service center," in IEEE International Conference on Robotics and Automation, 2002.

[305] S. Waldherr, R. Romero, and S. Thrun, "A gesture based interface for humanrobot interaction," Autonomous Robots, vol. 9, no. 2, pp. 151-173, 2000.

[306] M. L. Walters, K. Dautenhahn, R. te Boekhorst, K. L. Koay, C. Kaouri, S. Woods, C. Nehaniv, D. Lee, and I. Werry, "The influence of subjects' personality traits on personal spatial zones in a human-robot interaction experiment," in IEEE International Workshop on Robot and Human Interactive Computing (ROMAN), 2005.

[307] M. L. Walters, K. Dautenhahn, S. N. Woods, and K. L. Koay, "Robot etiquette: Results from user studies involving a fetch and carry task," in ACM/IEEE International Conference on Human-Robot Interaction, 2007.

[308] J. Wang, M. Lewis, and P. Scerri, "Cooperating robots for search and rescue," in Proceedings of AAMAS '06, Hakodate, Japan, 2005.

[309] Webster's Seventh New Collegiate Dictionary. Springfield, MA: G. and C. Merriam Company, 1966.

[310] C. R. Weisbin and G. Rodriguez, "NASA robotics research for planetary surface exploration," IEEE Robotics and Automation Magazine, vol. 7, no. 4, pp. 25-34, 2000.

[311] P. Wells and D. Deguire, "TALON: A universal unmanned ground vehicle platform, enabling the mission to be the focus," in Proceedings of SPIE Unmanned Ground Vehicle Technology VII, 2005.

[312] I. Werry, K. Dautenhahn, B. Ogden, and W. Harwin, "Can social interaction skills be taught by a social agent? The role of a robotic mediator in autism therapy," in Fourth International Conference on Cognitive Technology, Warwick, UK: Springer-Verlag, 2001.

[313] L. L. Whitcomb, "Underwater robotics: Out of the research laboratory and into the field," in IEEE International Conference on Robotics and Automation, 2000 . 
[314] C. D. Wickens and J. G. Hollands, Engineering Psychology and Human Performance. Prentice-Hall, 3rd ed., 2000.

[315] N. Wiener, God and Golem Inc.: A Comment on Certain Points where Cybernetics Impinges on Religion. Cambridge, MA, USA: MIT Press, 1966.

[316] Wikipedia, Wooden ox created by Zhuge Liang. 2007. Available from: http://en.wikipedia.org/wiki/Wooden_ox.

[317] B. Wilcox and T. Nguyen, "Sojourner on mars and lessons learned for future planetary rovers," in SAE International Conference on Environmental Systems, Danvers, MA, USA, 1998.

[318] A. Wolf, H. B. Brown, R. Casciola, A. Costa, M. Schwerin, E. Shamas, and H. Choset, "A mobile hyper redundant mechanism for search and rescue tasks," in 2003 IEEE/RSJ International Conference on Intelligent Robots and Systems, 2003.

[319] D. D. Woods, "Designs are hypotheses about how artifacts shape cognition and collaboration," Ergonomics, vol. 41, pp. 168-173, 1998.

[320] D. D. Woods, "Steering the reverberations of technology change on fields of practice: Laws that govern cognitive work," in Annual Meeting of the Cognitive Science Society, 2002.

[321] M. Wooldridge, Reasoning about Rational Agents. Cambridge, MA: MIT Press, 2000.

[322] Workshop on the Human Factors of UAVs 2004-2006.

[323] F. Yamaoka, T. Kanda, H. Ishiguro, and N. Hagita, "Lifelike behavior of communication robots based on developmental psychology findings," in IEEERAS International Conference on Humanoid Robots, 2005.

[324] H. A. Yanco, "Development and testing of a robotic wheelchair system for outdoor navigation," in Rehabilitation Engineering and Assistive Technology Society of North America Conference, RESNA Press, 2001.

[325] H. A. Yanco, J. L. Drury, and J. Scholtz, "Beyond usability evaluation: Analysis of human-robot interation at a major robotics competition," HumanComputer Interaction, vol. 19, no. 1-2, pp. 117-149, 2004.

[326] W. B. Yeats, The Winding Stair and Other Poems. Reprinted by Kessinger Publishing, 1933.

[327] M. Yim, "Astronauts must program," in To Boldly Go Where No HumanRobot Team Has Gone Before: Papers from the 2006 Spring Symposium, Menlo Park, CA, USA: AAAI, 2006.

[328] L. Youkou, Book of Master Lie. circa 500 BCE.

[329] J. Yuh, "Design and control of autonomous underwater robots: A survey," Autonomous Robots, vol. 8, no. 1, pp. 7-24, 2000.

[330] Z. Zenn Bien and H. E. Lee, "Effective learning system techniques for humanrobot interaction in service environment," Knowledge-Based Systems, vol. 20, no. 5, pp. 439-456, 2007. 